\title{
International consensus on (ICON) anaphylaxis
}

F Estelle R Simons ${ }^{1 *}$, Ledit RF Ardusso ${ }^{2}$, M Beatrice Bilò $^{3}$, Victoria Cardona ${ }^{4}$, Motohiro Ebisawa ${ }^{5}$, Yehia M El-Gamal ${ }^{6}$, Phil Lieberman ${ }^{7}$, Richard F Lockey ${ }^{8}$, Antonella Muraro ${ }^{9}$, Graham Roberts ${ }^{10}$, Mario Sanchez-Borges ${ }^{11}$, Aziz Sheikh ${ }^{12}$, Lynette P Shek $^{13}$, Dana V Wallace ${ }^{14}$ and Margitta Worm ${ }^{15}$

\begin{abstract}
ICON: Anaphylaxis provides a unique perspective on the principal evidence-based anaphylaxis guidelines developed and published independently from 2010 through 2014 by four allergy/immunology organizations. These guidelines concur with regard to the clinical features that indicate a likely diagnosis of anaphylaxis - a life-threatening generalized or systemic allergic or hypersensitivity reaction.

They also concur about prompt initial treatment with intramuscular injection of epinephrine (adrenaline) in the mid-outer thigh, positioning the patient supine (semi-reclining if dyspneic or vomiting), calling for help, and when indicated, providing supplemental oxygen, intravenous fluid resuscitation and cardiopulmonary resuscitation, along with concomitant monitoring of vital signs and oxygenation. Additionally, they concur that $\mathrm{H}_{1}$-antihistamines, $\mathrm{H}_{2}$-antihistamines, and glucocorticoids are not initial medications of choice.

For self-management of patients at risk of anaphylaxis in community settings, they recommend carrying epinephrine auto-injectors and personalized emergency action plans, as well as follow-up with a physician (ideally an allergy/immunology specialist) to help prevent anaphylaxis recurrences.

ICON: Anaphylaxis describes unmet needs in anaphylaxis, noting that although epinephrine in $1 \mathrm{mg} / \mathrm{mL}$ ampules is available worldwide, other essentials, including supplemental oxygen, intravenous fluid resuscitation, and epinephrine auto-injectors are not universally available.

ICON: Anaphylaxis proposes a comprehensive international research agenda that calls for additional prospective studies of anaphylaxis epidemiology, patient risk factors and co-factors, triggers, clinical criteria for diagnosis, randomized controlled trials of therapeutic interventions, and measures to prevent anaphylaxis recurrences. It also calls for facilitation of global collaborations in anaphylaxis research.

In addition to confirming the alignment of major anaphylaxis guidelines, ICON: Anaphylaxis adds value by including summary tables and citing 130 key references. It is published as an information resource about anaphylaxis for worldwide use by healthcare professionals, academics, policy-makers, patients, caregivers, and the public.
\end{abstract}

Keywords: Anaphylaxis, Acute systemic allergic reaction, Epinephrine (adrenaline), $\mathrm{H}_{1}$-antihistamines, $\mathrm{H}_{2}$-antihistamines, Glucocorticoids, Food allergy, Venom allergy, Drug allergy, Exercise-induced anaphylaxis, Idiopathic anaphylaxis

\footnotetext{
* Correspondence: Imcniven@hsc.mb.ca

${ }^{1}$ Department of Pediatrics \& Child Health and Department of Immunology, Faculty of Medicine, University of Manitoba, Room FE125, 820 Sherbrook

Street, Winnipeg, Manitoba, Canada, R3A 1 R9

Full list of author information is available at the end of the article
} 


\section{Introduction}

The prevalence of allergic diseases is increasing worldwide, attributed in part to increased exposure to environmental allergens and pollutants; nevertheless, these diseases remain under-diagnosed and undertreated. Within the framework of the International Collaboration in Asthma, Allergy, and Immunology (iCAALL), the World Allergy Organization (WAO) and three member organizations of the WAO federation of allergy organizations (the American Academy of Allergy, Asthma and Immunology [AAAAI], the American College of Allergy, Asthma and Immunology [ACAAI], and the European Academy of Allergy and Clinical Immunology [EAACI]) have united to increase global awareness of allergic diseases and to promote their evidence-based management. In this collaborative outreach program, international consensus (ICON) documents are being published as resources to provide information about allergic diseases for physicians, other healthcare professionals, policymakers, patients, caregivers, and the public [1].

This ICON: Anaphylaxis paper focuses on the principal anaphylaxis guidelines developed and published independently by the collaborating organizations from 2010 through 2014 [2-4], other anaphylaxisrelevant guidelines and publications from these organizations [5-22], and more than 100 additional key publications [23-124] that contribute to the evidence base for diagnosis, management, and prevention of anaphylaxis. In addition, it describes unmet global needs in the diagnosis and treatment of anaphylaxis in high-, mid-, and low-resource countries [125-130] and proposes an international agenda for anaphylaxis research.

\section{Methods}

The ICON: Anaphylaxis author group was identified by the 2012-2013 WAO Board of Directors based on global representation and comprised mainly of allergy/immunology specialists who had contributed to previous national and international anaphylaxis publications.

The WAO Anaphylaxis Guidelines [2], the AAAAI/ ACAAI Anaphylaxis Guidelines (Practice Parameters) [3] and the EAACI Anaphylaxis Guidelines [4] were circulated to all co-authors, who reviewed them, responded to four sequential calls for input about them sent by e-mail during 2013, and supplied additional relevant references. Each call for input consisted of a series of detailed questions about anaphylaxis that focused on definition, diagnosis, treatment in healthcare settings, and post-discharge management including prevention of recurrences. Co-authors were asked to review the collaborating organizations' principal guidelines and identify areas where they concurred, areas where emphasis differed, and areas where little or no information was provided. They were also asked to provide their perspectives on unmet needs in anaphylaxis and propose topics for an international anaphylaxis research agenda. The co-author response rate was $100 \%$ to all but one call for input (86\%).

The lead author collated the responses. Areas where the co-authors failed to agree were discussed by e-mail correspondence. The lead author then drafted the ICON: Anaphylaxis manuscript, which was developed further by internal reviews by the coauthors (with 100\% participation) and revisions. This was followed by external review by the iCAALL Steering Group, final revisions, and submission for publication. The co-authors met in person to discuss the ICON: Anaphylaxis document on June 25, 2013 during the World Allergy \& Asthma Congress in Milan.

\section{Overview of collaborating organizations' principal anaphylaxis guidelines}

An overview of the unique aspects of the principal anaphylaxis guidelines published by collaborating organizations is provided in Table 1 [2-4]. Although they vary in some areas of emphasis and in style, length, and referencing, their recommendations on anaphylaxis are aligned with regard to clinical diagnosis, initial treatment, and prevention of recurrences.

The widely disseminated WAO Anaphylaxis Guidelines [2], developed by the WAO Special Committee on Anaphylaxis, are supported by global assessments of essentials for anaphylaxis diagnosis and treatment [5-7] and yearly updates [8,9] of the evidence supporting the recommendations made in the guidelines. They provide a comprehensive, practical view of anaphylaxis. The text is closely linked with detailed illustrations that focus on patient risk factors, co-factors that amplify anaphylaxis, mechanisms, triggers, principles of clinical diagnosis, treatment, and postdischarge management. The illustrations on clinical diagnosis and prompt initial treatment have been translated into numerous languages and globally distributed as posters, pocket cards, and patient information cards.

The AAAAI/ACAAI Anaphylaxis Guidelines (Practice Parameters) [3] were developed by the Joint Task Force on Practice Parameters (representing the AAAAI, the ACAAI, and the Joint Council of Allergy Asthma and Immunology), which has a long history of publishing practice parameters on anaphylaxis [10-12] and related subjects [13-16]. These guidelines feature detailed descriptions of many anaphylaxis 
Table 1 Overview of collaborating organizations' principal anaphylaxis guidelines ${ }^{1}$

\begin{tabular}{|c|c|c|c|}
\hline & WAO Guidelines & AAAAI/ACAAI ${ }^{2}$ Guidelines & EAACI Guidelines \\
\hline Year of publication & 2011 & 2010 & 2014 \\
\hline Authors & Simons FER et al (10 co-authors) & Lieberman P et al (15 contributors) & Muraro A et al (28 co-authors) \\
\hline $\begin{array}{l}\text { Countries represented } \\
\text { by authors }\end{array}$ & $\begin{array}{l}\text { Argentina, Canada, Egypt, Germany, } \\
\text { Italy, Singapore United Kingdom, } \\
\text { United States, Venezuela }\end{array}$ & United States & $\begin{array}{l}\text { Canada, Denmark, France, } \\
\text { Germany, Italy, Ireland, The } \\
\text { Netherlands, Poland, Portugal, } \\
\text { Spain, Switzerland, United Kingdom }\end{array}$ \\
\hline Methods & consensus & consensus & $\begin{array}{l}\text { consensus using AGREE II } \\
\text { methodology }\end{array}$ \\
\hline $\begin{array}{l}\text { Length (number of } \\
\text { journal pages) }\end{array}$ & 7 page summary, 22 e-pages & 4 page summary, 30 e-pages & 20 pages \\
\hline References & total: $150 ; 80 \%$ published 2006-13 & total: 311; 13\% published 2006-13 & total: $133 ; 68 \%$ published 2006-13 \\
\hline $\begin{array}{l}\text { Tables, Figures, Boxes, } \\
\text { Appendices }\end{array}$ & 9 tables; 5 figures (illustrations) & 8 e-tables; 4 e-figures (algorithms) & $\begin{array}{l}2 \text { figures (algorithms); } 15 \text { boxes; } \\
4 \text { online supplements }\end{array}$ \\
\hline Dissemination and uptake & $\begin{array}{l}\text { key figures on diagnosis and treatment } \\
\text { translated }{ }^{3} \text { and widely disseminated } \\
\text { as posters, pocket cards and patient } \\
\text { information cards }\end{array}$ & $\begin{array}{l}\text { utilized by allergy/immunology } \\
\text { specialists }\end{array}$ & published in 2014 \\
\hline Unique aspects & $\begin{array}{l}\text { developed and funded by WAO; } \\
\text { evidence-based; global perspective; } \\
\text { key points highlighted using color } \\
\text { illustrations; allergists' role highlighted; } \\
\text { anaphylaxis in limited-resource areas } \\
\text { discussed; research agenda }\end{array}$ & $\begin{array}{l}\text { developed and funded by AAAAI/ } \\
\text { ACAAI/Joint Council'; evidence-based; } \\
\text { detailed information on triggers; } \\
\text { specific information on refractory } \\
\text { anaphylaxis; allergists' role highlighted }\end{array}$ & $\begin{array}{l}\text { developed and funded by EAACl; } \\
\text { evidence-based; participants from } \\
\text { many disciplines; allergists' role } \\
\text { highlighted; emphasis on practical } \\
\text { aspects of long-term management; } \\
\text { research agenda }\end{array}$ \\
\hline
\end{tabular}

${ }^{1}$ See text pages 2-3 for details, ${ }^{2}$ developed by the Joint Task Force on Practice Parameters, the AAAAl, the ACAAl, and the Joint Council of Allergy Asthma and Immunology, ${ }^{3}$ available in Arabic, English, French, German, Italian, Japanese, Korean (2014), Mandarin (2014), Polish, Portuguese, Russian, Spanish, and Turkish.

triggers and of idiopathic anaphylaxis. They describe clinical and laboratory diagnosis, initial treatment of anaphylaxis, treatment of refractory anaphylaxis, and post-discharge management. Many allergy/immunology specialists self-report adherence to these guidelines [17].

The EAACI 2014 Guidelines [4] were developed according to the Institute of Medicine Guidelines for Clinical Practice [18]. Co-authors included: allergy/ immunology specialists, emergency medicine specialists, population health scientists, primary care physicians, and representatives from patient organizations. These guidelines are supported by previous guidelines [19] and relevant concurrent publications that include systematic reviews of the epidemiology of anaphylaxis [20] and management of anaphylaxis [21], and the EAACI Food Allergy Guidelines [22]. They emphasize the role of anaphylaxis education in long-term management and provide practical recommendations for training physicians, other healthcare professionals, patients, and caregivers [4].

\section{Comparative review of collaborating organizations' principal anaphylaxis guidelines}

Scrutiny of collaborating organizations' guidelines reveals many areas of consensus, some areas where emphasis differs, and a few areas where minimal information is provided [2-4] (Table 2, 3, 4, and 5). Additional key publications representing global anaphylaxis research relevant to each area are cited as resources [5-124].

\section{Definition of anaphylaxis}

In these guidelines, the independently developed definitions of anaphylaxis for clinical use by healthcare professionals all include the concepts of a serious, generalized or systemic, allergic or hypersensitivity reaction that can be life-threatening or fatal. Importantly, none of the definitions include the word "shock" [2-4] (Table 2). The correct term "anaphylaxis" is preferred to "anaphylactic shock" because shock is not necessarily present in patients with anaphylaxis [23-26]. The term "anaphylaxis" should also be used in preference to terms such as "allergic reaction", "acute allergic reaction", "systemic allergic reaction", "acute IgE-mediated reaction", "anaphylactoid reaction", or "pseudo-anaphylaxis" [2-4].

\section{Epidemiology}

None of the guidelines has a major focus in this area [2-4]; however, they all include important information about anaphylaxis epidemiology supported by relevant references [2-4,27-37] (Table 2).

\section{Patient-specific risk factors and co-factors relevant to anaphylaxis}

The guidelines concur about the importance of patientspecific risk factors and co-factors in anaphylaxis [2-4]. 
Table 2 Essential information on anaphylaxis: summary of collaborating organizations' principal anaphylaxis guidelines $^{1}$

\begin{tabular}{llll}
\hline & WAO Guidelines & AAAAI/ACAAI Guidelines & EAACI Guidelines \\
\hline Definition of anaphylaxis & "a serious life-threatening & "an acute life-threatening & "a severe life-threatening \\
& generalized or systemic & gystemic reaction with varied & generalized or systemic \\
& hypersensitivity reaction" & mechanisms, clinical presentations, & hypersensitivity reaction" \\
& and "a serious allergic & and severity that results from & \\
& reaction that is rapid in & the sudden release of mediators &
\end{tabular}

Epidemiology onset and might cause death"

not a major emphasis from mast cells and basophils"

not a major emphasis

describe concomitant diseases (asthma, CVD, mastocytosis), concurrent medications (beta-blockers, ACE inhibitors); mention premenstrual status as a co-factor

describe vulnerability related to age, concomitant diseases (asthma, CVD, mastocytosis), concurrent medications (beta-blockers, ACE inhibitors); describe co-factors such as exercise, acute infection, emotional stress, premenstrual status, and ethanol or NSAID ingestion; Figure 1

Underlying mechanisms

provide an overview of immunologic mechanisms (lgE-dependent and lgE-independent), non-immunologic (direct mast cell activation) and idiopathic anaphylaxis (no apparent trigger); Figure 2

Anaphylaxis triggers
(causes, elicitors, or
inducers)

describe most triggers; state that the relative importance of specific triggers varies in different age groups and different global regions; Figure 2 describe immunologic mechanisms in the context of different anaphylaxis triggers; describe idiopathic anaphylaxis; Table E7

describe many triggers in detail, with major emphasis on foods, venoms, drugs, biological agents, perioperative agents, radiocontrast media, latex, exercise, human seminal fluid, and idiopathic anaphylaxis; Table E5 summary of anaphylaxis epidemiology and clinical presentation: gaps in the evidence (Box 15)

give examples of patientspecific factors, pre-existing conditions, medications and lifestyle factors; describe concomitant asthma in detail; Box 6

major focus on lgE-mediated anaphylaxis to food, insect venoms, and drugs; other mechanisms are mentioned

overview of some triggers; describe food triggers in considerable detail; state that the importance of triggers varies with age and geography

${ }^{1}$ For details, see ICON: Anaphylaxis text pages 3-5 and references 2, 3 and 4, including the tables, figures, and boxes that are mentioned above in this Table. ACE, angiotensin-converting enzyme; CVD, cardiovascular disease; NSAID, non-steroidal anti-inflammatory drug.

The WAO Guidelines emphasize risk factors related to age (infancy, adolescence, advanced age), physiologic state (pregnancy), concomitant diseases including asthma, cardiovascular diseases (CVD), and mastocytosis, and concurrent medications such as beta-blockers and angiotensinconverting enzyme (ACE) inhibitors. The AAAAI/ACAAI Guidelines describe patient-specific risk factors such as asthma, CVD, and mastocytosis, and concurrent betablocker and ACE-inhibitor use. The EAACI Guidelines include a major focus on asthma as a patient risk factor (Table 2).

The guidelines also concur about the relevance of co-factors that amplify [2-4] anaphylaxis. The WAO Guidelines and EAACI Guidelines provide an overview of co-factors such as exercise, emotional stress, acute infection, fever, concomitant ingestion of ethanol or a nonsteroidal anti-inflammatory drug (NSAID), disruption of routine, and perimenstrual status. The AAAAI/ACAAI Guidelines focus on exercise. The importance of risk factors [38-49] and amplifying co-factors $[33,50,51]$ that potentially impact anaphylaxis is now widely acknowledged; indeed, co-factors are now reported to be relevant in $20-30 \%$ of anaphylactic episodes [33,50].

None of the guidelines describe the relationship between mast cell activation disorders (MCAD) and anaphylaxis, perhaps because the first international consensus document on classification of MCAD was only published in 2012 [45].

\section{Underlying mechanisms}

The WAO Guidelines provide a brief overview of IgEdependent and IgE-independent immunologic mechanisms and direct mast cell stimulation in anaphylaxis [2]. The AAAAI/ACAAI Guidelines describe immunologic mechanisms and direct mast cell activation in the context of different triggers [3]. The EAACI Guidelines focus mainly on IgE-mediated anaphylaxis [4] (Table 2).

None of the guidelines provide optimal information on IgG-mediated anaphylaxis in humans, an emerging area of investigation [52]. 
Table 3 Diagnosis of anaphylaxis: summary of collaborating organizations' principal anaphylaxis guidelines ${ }^{1}$

\begin{tabular}{|c|c|c|c|}
\hline & WAO Guidelines & AAAAI/ACAAI Guidelines & EAACI Guidelines \\
\hline $\begin{array}{l}\text { Symptoms and signs } \\
\text { (typically within minutes to } \\
\text { hours after exposure; multi- } \\
\text { system; rapid progression) }\end{array}$ & $\begin{array}{l}\text { describe symptoms and signs in } \\
\text { detail; Table } 2\end{array}$ & $\begin{array}{l}\text { describe symptoms and signs; list } \\
\text { frequency of symptoms and signs in } \\
\text { different organ systems; Table E1 }\end{array}$ & $\begin{array}{l}\text { describe symptoms and signs; } \\
\text { Figure } 1\end{array}$ \\
\hline $\begin{array}{l}\text { Clinical criteria for diagnosis } \\
\text { of anaphylaxis }\end{array}$ & $\begin{array}{l}\text { primary emphasis on clinical diagnosis; } \\
\text { clinical criteria for diagnosis are listed } \\
\text { and illustrated; Table 1, Figure } 3\end{array}$ & $\begin{array}{l}\text { primary emphasis on clinical } \\
\text { diagnosis: state "the history is the } \\
\text { most important tool"; clinical criteria } \\
\text { for diagnosis are listed; Figure E1 }\end{array}$ & $\begin{array}{l}\text { primary emphasis on clinical } \\
\text { diagnosis: clinical criteria for } \\
\text { diagnosis are listed; Box } 4\end{array}$ \\
\hline $\begin{array}{l}\text { Laboratory tests for } \\
\text { confirmation of the } \\
\text { clinical diagnosis }\end{array}$ & $\begin{array}{l}\text { describe use of tryptase or histamine } \\
\text { measurements and other tests in a } \\
\text { supportive role; emphasize correct } \\
\text { timing of blood samples; Table } 3\end{array}$ & $\begin{array}{l}\text { describe use of tryptase or histamine } \\
\text { measurements and other tests in a } \\
\text { supportive role; emphasize correct } \\
\text { timing of blood samples; Table E3 }\end{array}$ & $\begin{array}{l}\text { describe use of tryptase } \\
\text { measurements in a } \\
\text { supportive role }\end{array}$ \\
\hline Differential diagnosis & $\begin{array}{l}\text { comprehensive list provided; additional } \\
\text { laboratory tests for ruling out other } \\
\text { diagnoses are described; Table } 4\end{array}$ & $\begin{array}{l}\text { comprehensive list provided; } \\
\text { additional laboratory tests for ruling } \\
\text { out other diagnoses are described; } \\
\text { Tables E2, E3 }\end{array}$ & $\begin{array}{l}\text { comprehensive list provided, } \\
\text { including detailed list of } \\
\text { neuropsychiatric diseases; Box } 5\end{array}$ \\
\hline $\begin{array}{l}\text { Diagnosis of anaphylaxis in } \\
\text { special populations }\end{array}$ & $\begin{array}{l}\text { include reference ranges for vital signs } \\
\text { in infants and children, and discuss } \\
\text { relevant clinical and lab issues in infants, } \\
\text { pregnant women and the elderly; Figure } 1\end{array}$ & $\begin{array}{l}\text { include normal values for vital signs in } \\
\text { infants and children; Table E4 }\end{array}$ & $\begin{array}{l}\text { describe patient-specific } \\
\text { factors: examples include } \\
\text { adolescence, advanced age, } \\
\text { and gender; Box } 6\end{array}$ \\
\hline
\end{tabular}

${ }^{1}$ For details, see ICON: Anaphylaxis text page 5 and references 2, 3, and 4, including the tables, figures, and boxes from these references that are mentioned above in this Table.

\section{Anaphylaxis triggers (Causes, Elicitors, or Inducers)}

The WAO Guidelines describe triggers and idiopathic anaphylaxis concisely, and note that different triggers predominate in different age groups and different global regions [2]. The AAAAI/ACAAI Guidelines provide detailed information about many triggers including foods, stinging insect venoms, drugs, biological agents, perioperative agents, radiocontrast media, latex, subcutaneous allergen immunotherapy, and human seminal fluid; also about idiopathic anaphylaxis [3]. The EAACI Guidelines emphasize food triggers, provide information on stinging insect venom and drug triggers, and state that the relative importance of triggers varies with age and geography [4] (Table 2).

Anaphylaxis triggers such as food, venom, and drugs have been studied in Australia, Europe, North America, and beyond; for example, in Asia (China, Japan, Korea, Singapore, and Thailand), and South America (Argentina, Brazil, and Venezuela) [27-37,53-66]. In any region, the relative importance of triggers can change over time [54].

\section{Clinical diagnosis of anaphylaxis}

Collaborating organizations' guidelines concur about making the clinical diagnosis of anaphylaxis based on recognition of sudden onset of characteristic symptoms and signs within minutes to hours after exposure to a known or likely trigger [2-4]. They all list the clinical criteria for diagnosis of anaphylaxis that were developed as an instrument for rapid assessment of patients who present with a possible diagnosis of anaphylaxis [23] and are validated for use in medical settings and in epidemiologic studies $[67,68]$ (Table 3 ).
The guidelines also concur that laboratory tests are not helpful in diagnosing anaphylaxis at the time of patient presentation [2-4]. Measurement of a biologic marker such as serum total tryptase takes hours and test results are not available on an emergency basis. Elevation in biologic marker levels correlates with anaphylaxis severity [24]; platelet-activating factor levels appear to correlate better than tryptase or histamine levels do [69]. Tryptase levels are elevated in only about $60 \%$ of adults with clinically confirmed anaphylaxis [70] and are seldom elevated in children with anaphylaxis or in food-induced anaphylaxis. The reference range for tryptase levels in infants has been established [71]. Tryptase levels (or levels of any other biologic markers) within the normal reference range do not rule out anaphylaxis. Lack of availability of biologic marker measurements is not a barrier to prompt clinical diagnosis of anaphylaxis [2-4].

In addition to the above, all the guidelines provide a perspective on the differential diagnosis of anaphylaxis [2-4] (Table 3).

\section{Prompt initial treatment of anaphylaxis}

Importantly, collaborating organizations' guidelines concur with regard to recommendations for prompt initial treatment of anaphylaxis with epinephrine (adrenaline) injected intramuscularly in the mid-outer thigh, and repeating the epinephrine dose after 5-15 minutes if the response to the first injection is not optimal [2-4] (Table 4).

The guidelines concur about the importance of preparedness to diagnose and treat anaphylaxis and about other measures such as rapid assessment of the patient, removing the trigger if possible, and calling for help. 
Table 4 Anaphylaxis treatment in healthcare settings: summary of collaborating organizations' principal anaphylaxis guidelines ${ }^{1}$

\begin{tabular}{|c|c|c|c|}
\hline & WAO Guidelines & AAAAI/ACAAI ${ }^{2}$ Guidelines & $\mathrm{EAACl}^{3}$ Guidelines \\
\hline $\begin{array}{l}\text { Prompt initial treatment } \\
\text { of anaphylaxis }\end{array}$ & $\begin{array}{l}\text { have a protocol; remove the } \\
\text { trigger, if relevant, assess rapidly, } \\
\text { promptly and simultaneously call } \\
\text { for help, inject epinephrine IM, } \\
\text { repeat in 5-15 min, position the } \\
\text { patient supine (semi-reclining if } \\
\text { dyspneic or vomiting) with lower } \\
\text { extremities elevated; Tables 5, 6, } \\
\text { 7; Figure } 4\end{array}$ & $\begin{array}{l}\text { epinephrine IM is the initial } \\
\text { medication of choice; repeat } \\
\text { in } 5+\text { min; have a protocol; } \\
\text { remove exposure to the trigger; } \\
\text { position the patient supine } \\
\text { (semi-reclining if dyspneic or } \\
\text { vomiting) with lower extremities } \\
\text { elevated; call for help; Figures } \\
\text { E2, E3 }\end{array}$ & $\begin{array}{l}\text { 1st-line treatment: inject } \\
\text { epinephrine IM; repeat in } \\
10 \text { min; } 2^{\text {nd }} \text {-line treatment: } \\
\text { inhaled beta-2 agonists for } \\
\text { wheezing; inhaled adrenaline } \\
\text { for stridor; remove the trigger, } \\
\text { call for help, position the patient } \\
\text { appropriately, high-flow oxygen, } \\
\text { fluid support (crystalloid); Boxes } \\
7,8,15 \text {; online supplement; Figure } 2\end{array}$ \\
\hline Initial treatment (cont.) & $\begin{array}{l}\text { when indicated, give supplemental } \\
\text { high-flow oxygen; IV fluids (crystalloid); } \\
\text { start cardiopulmonary resuscitation } \\
\text { with continuous chest compressions; } \\
\mathrm{H}_{1} \text { - and } \mathrm{H}_{2} \text {-antihistamines, beta-2 } \\
\text { agonists, and glucocorticoids are } \\
2^{\text {nd }} \text {-line medications; Tables 5, 6, 7, 8; }\end{array}$ & $\begin{array}{l}\text { supplemental oxygen; IV fluid } \\
\text { (crystalloid or colloid); } \\
\text { cardiopulmonary resuscitation; } \\
\mathrm{H}_{1} \text { - and } \mathrm{H}_{2} \text {-antihistamines, inhaled } \\
\text { beta-2 agonists, and glucocorticoids } \\
\text { are not initial medications of choice; } \\
\text { Figures E2, E3 }\end{array}$ & $\begin{array}{l}3^{\text {rd }} \text {-line interventions: } \mathrm{H}_{1} \text { - and } \\
\mathrm{H}_{2} \text {-antihistamines, glucocorticoids; } \\
\text { protocol for initial management } \\
\text { includes cardiopulmonary } \\
\text { resuscitation; systematic review of } \\
\text { emergency management; Boxes } \\
\text { 7, 15; online supplement; Figure } 2\end{array}$ \\
\hline
\end{tabular}

Management of refractory intubation; ventilation; IV vasopressors; anaphylaxis

glucagon; anticholinergic; transfer to hospital (preferably to an emergency medicine, critical care medicine, or anesthesiology) team for ventilatory and inotropic support; checklist of needed items; Table 6

Observation and
monitoring in healthcare
settings

observe for minimum 4 hrs; 8-10 hrs if respiratory or cardiovascular compromise; monitor $\mathrm{BP}$, cardiac rate and function, respiratory status and oxygenation at frequent regular intervals, eg. 1-5 mins; continuous electronic monitoring if possible (essential if giving vasopressors); Table 5; Figure 4 vasopressors; dopamine; give vasopressin if epinephrine injections and volume expansion fail to alleviate hypotension; transfer to hospital; glucagon; atropine; methylene blue; includes checklist of supplies and equipment; Figures E2, E3

individualize duration of observation; monitor $\mathrm{BP}$ and heart rate at frequent regular intervals (eg. 1 minute); continuous monitoring of $\mathrm{BP}$, heart rate and function, and oxygenation, if possible; an example of a treatment record form for use in patients with anaphylaxis is provided; Figures E2, E4 glucagon

minimum duration of observation 6-8 hrs for patients with respiratory symptoms and 12-24 hrs for those with hypotension or collapse; need for monitoring is highlighted; Box 7; online supplement; Figure 2

\footnotetext{
${ }^{1}$ For details, see ICON: Anaphylaxis text pages 5-8 and references 2, 3, and 4, including the tables, figures, boxes, and online supplemental materials from these references that are mentioned above in this Table.

${ }^{2}$ In the AAAAI/ACAAI Practice Parameters, one algorithm describes initial evaluation and management of a patient with a history of a previous episode of anaphylaxis and another algorithm describes treatment of an anaphylactic event in the outpatient setting.

${ }^{3}$ An evidence-based review of effectiveness of interventions for acute and long-term management is published separately.

BP, blood pressure; IM, intramuscular; IV, intravenous.
}

They all recommend positioning the patient supine (or semi-reclining in a position of comfort if dyspneic or vomiting) with elevation of the lower extremities [2-4].

The guidelines also concur that if indicated at any time, supplemental oxygen, intravenous (IV) fluid resuscitation with a crystalloid such as $0.9 \%$ (isotonic) saline, and cardiopulmonary resuscitation should be started without delay [2-4] and that $\mathrm{H}_{1}$-antihistamines, $\mathrm{H}_{2}$-antihistamines, and glucocorticoids are not initial medications of choice [72-75].

There are a few differences in emphasis among the guidelines with regard to initial treatment of anaphylaxis. The WAO Guidelines include the revised resuscitation guidelines recommendations for starting cardiopulmonary resuscitation with chest compressions before giving rescue breaths, allowing time for complete chest recoil, and minimizing interruptions for pulse checks $[2,76]$. The WAO Guidelines and AAAAI/ACAAI Guidelines describe epinephrine injection, calling for help, and positioning the patient appropriately as concurrent initial steps [2,3], while the EAACI Guidelines describe epinephrine injection as a first-line intervention and calling for help and positioning as second-line interventions [4]. The WAO Guidelines and the AAAAI/ACAAI Guidelines do not specifically recommend inhaled epinephrine for patients with stridor during anaphylaxis, although they note that an inhaled beta-2 agonist should be considered in patients with bronchospasm that persists despite epinephrine treatment $[2,3]$. The EAACI Guidelines recommend inhaled epinephrine (adrenaline) in patients with stridor and an inhaled beta- 2 adrenergic agonist in patients with wheezing after, and in addition to, epinephrine injection [4] (Table 4).

None of the guidelines discuss epinephrine injection in high-risk patients after exposure to a relevant trigger but 
Table 5 Anaphylaxis in community settings: summary of collaborating organizations' principal anaphylaxis guidelines ${ }^{1}$

\begin{tabular}{|c|c|}
\hline & WAO Guidelines \\
\hline $\begin{array}{l}\text { Post-discharge management of } \\
\text { patients treated for acute } \\
\text { anaphylaxis }\end{array}$ & $\begin{array}{l}\text { prescribe epinephrine IM } \\
\text { through auto-injector; anaphylaxis } \\
\text { emergency action plan; medical } \\
\text { ID stating triggers and } \\
\text { co-morbidities; Table 9, Figure } 5\end{array}$ \\
\hline
\end{tabular}

\section{Investigations by allergy/ immunology specialists to confirm anaphylaxis triggers}

\section{Prevention of anaphylaxis recurrences}

\author{
Anaphylaxis education and \\ training
}

Follow-up with physician when needed to distinguish

AAAAI/ACAAI Guidelines
prescribe epinephrine IM through
auto-injector; anaphylaxis emergency
action plan; medical ID; "an action
plan is an important component of
follow-up"; Figure E1

state the importance of the history of the episode; describe skin prick tests (intradermal tests needed for venom and drug-triggered anaphylaxis); investigations in idiopathic anaphylaxis; additional tests allergen sensitization from clinical risk in patients with food or drug allergy; Table 9, Figure 5 describe investigations in detail under different triggers; describe investigations in idiopathic anaphylaxis; details on skin testing with anesthetic agents; Table E8

\section{EAACI Guidelines}

prescribe epinephrine IM through auto-injector; provide discharge advice sheet; provide specialist referral and contact information for patient support groups; Boxes $7,9,10,11,12,13,14,15$

state "validated in vivo and/or in vitro tests should be interpreted in the light of a detailed allergy history"; additional information re investigations to confirm food triggers is published separately in the EAACI Food Allergy Guidelines describe allergen avoidance (food, stinging insects, drugs, latex, etc.); immunotherapy with standardized insect venoms; and desensitization to drugs; mention food $\mathrm{OlT}^{2}$; describe pharmacologic prophylaxis of RCM anaphylaxis and idiopathic anaphylaxis; Table 9, Figure 5

outline principles of anaphylaxis education describe specific avoidance measures under triggers; describe venom immunotherapy and desensitization to drugs; describe pharmacologic prophylaxis of RCM anaphylaxis and idiopathic anaphylaxis; Table E6; Figure E1

provide relevant information under various triggers; give examples of print resources; Figure E1

review discharge management, allergen avoidance, and immune modulation describe food avoidance; venom immunotherapy and desensitization to drugs; mention food $\mathrm{OlT}^{2}$; describe pharmacologic prophylaxis of anaphylaxis to RCM and snake anti-venom; Boxes 8, 9, 15; online supplement

major emphasis on all aspects of anaphylaxis training and adrenaline auto-injector prescription; Boxes 9, 10, $11,12,13,14,15$; online supplement

yearly review of EAI use, action plan, optimal management of co-morbid diseases, adjustment of concurrent medications as needed, allergen avoidance, and immune modulation major emphasis; include

recommendations for training, management plan, and if relevant, help from nutritionists and psychologists; Boxes 9, 15; online supplement

${ }^{1}$ For details, see ICON: Anaphylaxis text pages 8-9 and references 2, 3, and 4, including the tables, figures, boxes, and online supplemental materials from these references that are mentioned above in this Table.

${ }^{2}$ Described but not recommended for clinical implementation at this time.

EAl, epinephrine auto-injector; ID, identification; IM, intramuscular; OIT, oral immunotherapy; RCM, radiocontrast media.

before symptoms develop and none discuss epinephrine administration to a patient diagnosed incorrectly with anaphylaxis, perhaps because there is little or no published information on either of these issues.

Epinephrine utilization in anaphylaxis remains an active area of research. The need for prompt epinephrine use to prevent escalation of mediator release in anaphylaxis has been confirmed in a new in vitro model [77]. Use of multiple epinephrine injections does not necessarily correlate with patient obesity [78]. Rates of epinephrine utilization as the initial medication for anaphylaxis in emergency departments are typically low [79]; however, they can be improved significantly with implementation of an anaphylaxis protocol $[80,81]$.

Management of anaphylaxis refractory to initial treatment The guidelines differ in emphasis on refractory anaphylaxis treatment. The WAO Guidelines stress the importance of prompt initial treatment to prevent escalation of symptoms [2]. They suggest that if possible, patients with anaphylaxis refractory to epinephrine, supplemental oxygen, IV fluids, and second-line medications should be transferred to the care of a specialist team for ventilatory and inotropic support and continuous electronic monitoring [2]. The AAAAI/ACAAI Guidelines provide details about interventions for cardiopulmonary arrest, airway management, and IV administration of vasopressors including epinephrine, dopamine, and vasopressin [3]. The EAACI Guidelines include brief specific instructions about when to call for Intensive Care Unit support [4] (Table 4).

Studies relevant to refractory anaphylaxis treatment are of interest. A Cochrane review of randomized controlled trials (RCT) in more than 20,000 critically ill patients with distributive shock supports administration of crystalloids such as $0.9 \%$ saline, because administration of colloids such as albumin or hetastarch did not 
correlate with increased survival [82]. Methylene blue administration for vasoplegia in anaphylaxis refractory to epinephrine and IV fluid resuscitation is based on case reports and extrapolation from use in other forms of shock [83].

\section{Observation and monitoring in healthcare settings}

The guidelines concur that patients with moderate or severe anaphylaxis, for example, those with moderate or severe respiratory or cardiovascular symptoms and signs should be observed and monitored for a longer duration (eg. at least 6-8 hours) than those with mild anaphylaxis. The WAO Guidelines note that duration of monitoring can also vary with patient age and co-morbidities, and with local conditions. The AAAAI and EAACI Guidelines provide additional information about biphasic anaphylaxis and protracted anaphylaxis [2-4] (Table 4).

In a prospective study in which mediator release in anaphylaxis was documented at sequential timed intervals, levels of some mediators correlated with delayed deterioration, supporting recommendations for safe observation periods after initial treatment [24].

The guidelines also concur that blood pressure, cardiac rate and function, respiratory status and oxygenation should be monitored clinically at frequent intervals (every 1-5 minutes), or if possible, continuously [2-4]. Lack of universal availability of continuous electronic monitoring and pulse oximetry remains a concern.

\section{Post-discharge management of patients treated for acute anaphylaxis}

Collaborating organizations' guidelines concur that management of anaphylaxis does not end with treatment of the anaphylactic episode [2-4] and that post-discharge management should include follow-up with a physician, preferably an allergy/immunology specialist [2,4,84-124] (Table 5).

The WAO Guidelines state that if epinephrine autoinjectors are not available, alternative, although not preferred, recommendations for epinephrine injection need to be provided (for details, please see the subsequent section on Post-Discharge Management on page 12 of this paper) $[2,6,7]$. They also note the importance of anaphylaxis emergency action plans and medical identification (ID) stating anaphylaxis triggers and co-morbid diseases. The AAAAI/ACAAI Guidelines recommend prescribing more than one epinephrine auto-injector because more than one dose of epinephrine is needed in about $20 \%$ of anaphylactic episodes; additionally, they recommend action plans and medical ID [3]. The EAACI Guidelines include comprehensive information about discharge management, for example, providing a discharge letter for the family doctor, as well as providing a discharge sheet for patients that contains information about epinephrine auto-injector use, allergen avoidance, and how to contact patient support groups. They also include detailed information about management plans, evidence-based absolute indications for prescription of at least one auto-injector, and suggested indications for prescription of a second auto-injector. They suggest strategies for training patients at risk and caregivers of patients at risk. Additionally, they list gaps in the evidence supporting recommendations for long-term management of anaphylaxis [4] (Table 5).

Post-discharge management of patients at risk for anaphylaxis recurrences in the community is an active area of research [84-98]. This focuses on patient and caregiver failure to carry auto-injectors and use autoinjectors for anaphylaxis $[87,88]$, patient, caregiver, and physician experiences in using auto-injectors [89-92], auto-injector redesign $[93,94]$ and education and support of patients at risk [95-97], an area in which additional high-quality studies are needed [98]. Although improved rates of filling epinephrine prescriptions after discharge from some emergency departments are reported $[85,86]$, for many patients lack of affordable auto-injectors remains a barrier to use [7].

\section{Investigations to confirm anaphylaxis triggers}

The guidelines concur that triggers should be confirmed by re-taking the history of the anaphylactic episode and using this as a guide to selection of allergens for skin prick tests, measurement of allergen-specific $\operatorname{IgE}$ levels in serum, and additional investigations as needed [2-4,13-15,22,53,99-106]. Intradermal tests are helpful in investigation of anaphylaxis induced by insect venoms or drugs such as beta-lactam antibiotics [103-106]. Negative skin tests and absent or undetectable allergen-specific IgE levels have a high negative predictive value; however, positive tests have a lower positive predictive value because allergen sensitization without symptoms is widespread in the general population. Ideally, tests to assess sensitization to allergens should be interpreted by an allergy/immunology specialist [2-4,13-15,22,53,64,99-106] (Table 5). Medicallysupervised incremental allergen challenge tests, indicated in some patients with food or drug allergy, should be conducted only by experienced healthcare professionals in settings where anaphylaxis can be treated promptly $[2-4,13,15,22,53,104,105]$.

None of the guidelines emphasize standardization of tests and challenges; perhaps because international consensus documents on standardization were only published in 2012 and 2013 [2-4,100,102].

\section{Prevention of anaphylaxis recurrences}

The guidelines concur about prevention of anaphylaxis recurrences by avoidance of confirmed allergens, including hidden or cross-reacting allergens [2-4,13-15,22,53,64,99, 
104,105,107-111]. Vigilant avoidance prevents anaphylaxis recurrence from culprit allergens [107,108]; however, it can be time-consuming, frustrating, difficult to sustain in daily life, and associated with impaired quality-of-life; including bullying of food-allergic children [109-111].

The guidelines concur in their recommendation for immune modulation to prevent recurrences of anaphylactic episodes from stinging insect venom [2-4,14,112-116] and drugs [2-4,15,117]. The WAO Guidelines and EAACI Guidelines describe oral immunotherapy (OIT) to prevent recurrences of food-induced anaphylaxis, but concur that this approach is not yet ready for general use [2,4,13,22,119] (Table 5).

For prevention of recurrence of stinging insect venominduced anaphylaxis, a 3-5 year course of subcutaneous immunotherapy with the relevant standardized specific venom(s) leads to long-lasting protection in most patients [2-4,14,112-115]; lifelong venom immunotherapy (VIT) is recommended in patients with mastocytosis [116].

For prevention of recurrent anaphylaxis from a drug such as an antibiotic or NSAID, or a biologic agent, when no safe substitute is available, desensitization conducted by experienced healthcare professionals using a published protocol is safe and effective for one uninterrupted course of treatment [2-4,15,104,105,117].

In carefully selected patients with symptoms after ingestion of milk, egg, peanut, or other highly allergenic food, RCT of OIT confirm that clinical desensitization can be achieved in most patients; however, sustained unresponsiveness after stopping treatment is more difficult to achieve, and adverse events, including anaphylaxis, occur $[99,119,120]$. OIT safety can be improved with omalizumab pre-treatment and co-treatment [99,121]. Sublingual immunotherapy to prevent food-induced anaphylaxis, although less effective than OIT, is associated with fewer adverse events $[99,120]$.

The guidelines differ in their emphasis on pharmacologic prophylaxis of anaphylaxis from various triggers. They all describe pharmacologic interventions to prevent anaphylaxis to radiocontrast media [2-4,64,122]. The WAO and the AAAAI/ACAAI Guidelines recommend pharmacologic prophylaxis in selected patients with idiopathic anaphylaxis $[2,3]$. The EAACI Guidelines provide information about pretreatment with epinephrine to prevent anaphylaxis to snake anti-venom $[4,123]$. Surprisingly, no guidelines provide information about pharmacological prophylaxis of anaphylaxis from subcutaneous allergen immunotherapy, although $\mathrm{H}_{1}$-antihistamine pre-treatment before venom injections during VIT reduces systemic adverse events and has a beneficial immune-modifying effect [124] (Table 5).

\section{Anaphylaxis education}

The guidelines differ in their emphasis on anaphylaxis education for patients and caregivers. The WAO Guidelines outline the principles of anaphylaxis education [2]. The AAAAI/ACAAI Guidelines discuss anaphylaxis education in the context of some specific triggers [3]. The EAACI Guidelines provide comprehensive information about anaphylaxis education, including information about long-term management, recommendations for training (with description of barriers to and facilitators of implementation), audit criteria, and resource implications [4] (Table 5).

None of the guidelines describe anaphylaxis education for personnel working in child care, schools, colleges, universities, summer camps, and sports facilities, or the hospitality or airline industries; however, a forthcoming EAACI publication addresses anaphylaxis education in the community-at-large (Muraro A, personal communication).

\section{Follow-up with a physician}

All the guidelines address the issue of follow-up with a physician [2-4], if possible with an allergy/immunology specialist. The WAO Guidelines recommend follow-up yearly for review of prevention of recurrence, epinephrine auto-injector use, and optimizing control of relevant co-morbid diseases such as asthma [2]. The AAAAI/ ACAAI Guidelines discuss specific aspects of follow-up in association with some of the major triggers [3]. In addition to physician follow-up, the WAO and EAACI Guidelines note the importance of follow-up with a dietician, if relevant, and the EAACI Guidelines also suggest follow-up with a psychologist, if relevant [4] (Table 5).

\section{Unmet needs in anaphylaxis}

Unmet needs in anaphylaxis in high-, mid-, and lowresource countries are described in Tables 6, 7, 8, and 9.

\section{Definition of anaphylaxis}

In all countries, increased awareness of anaphylaxis as a serious, life-threatening, generalized or systemic, allergic or hypersensitivity reaction with sudden onset (minutes to a few hours) is needed among healthcare professionals, patients, caregivers, and the public (Table 6).

\section{Epidemiology}

For epidemiologic purposes, the validated clinical criteria for anaphylaxis diagnosis are helpful for informing International Classification of Disease (ICD)-9 and ICD-10 codes and facilitating reliable estimates of anaphylaxis prevalence in healthcare settings [27-33] and to a lesser extent in the general population $[34,35]$.

In all countries, epidemiological and health services research can serve as a baseline for quality improvement, prioritization of anaphylaxis programs, and eventual reduction in morbidity and mortality. However, until diagnosis of anaphylaxis as such by healthcare professionals improves and recognition by patients, caregivers, and the public improves, it will remain difficult to obtain 
Table 6 Essential information on anaphylaxis: summary of unmet needs

\begin{tabular}{|c|c|c|}
\hline & High-resource countries $^{1}$ & Limited-resource countries $^{2}$ \\
\hline $\begin{array}{l}\text { Definition of anaphylaxis, eg. serious, } \\
\text { life-threatening generalized allergic } \\
\text { or hypersensitivity reaction }\end{array}$ & $\begin{array}{l}\text { need } \uparrow \text { awareness of a current anaphylaxis } \\
\text { definition for clinical use }\end{array}$ & $\begin{array}{l}\text { need } \uparrow \text { awareness of a current } \\
\text { anaphylaxis definition for } \\
\text { clinical use }\end{array}$ \\
\hline Epidemiology & $\begin{array}{l}\text { need integration of the clinical criteria for } \\
\text { diagnosis of anaphylaxis with ICD-9 and } \\
\text { ICD-10 codes; need more reliable prevalence } \\
\text { estimates in healthcare settings and in the } \\
\text { general population; and need more reliable } \\
\text { prevalence estimates of mortality rates }\end{array}$ & $\begin{array}{l}\text { need concurrent epidemiologic } \\
\text { studies of anaphylaxis using similar } \\
\text { methods in different countries in order } \\
\text { to obtain reliable prevalence estimates } \\
\text { in the general population }\end{array}$ \\
\hline
\end{tabular}

\section{Patient risk factors and co-factors relevant to anaphylaxis}

Underlying mechanisms

Triggers (causes, elicitors, or inducers) prevalence estimates of mortality rates from different triggers in different patient populations

need $\uparrow$ awareness of patient risk factors for severe or fatal anaphylaxis, eg. asthma, CVD and MCAD; and need $\uparrow$ awareness of the role of co-factors such as exercise, ethanol, NSAIDs, emotional stress, acute infection, perimenstrual status

need greater understanding of IgE-dependent, lgE-independent, and non-immunologic mechanisms (direct mast cell activation)

need improved standardization of allergens, a standardized mechanism for reporting novel triggers, and continued efforts to standardize protocols for skin tests and challenge tests need baseline information about the prevalence of asthma, CVD, and MCAD so their relationship with anaphylaxis can be ascertained; need $\uparrow$ awareness of potential patient risk factors and co-factors; insights might be obtained from studies of fatal episodes ${ }^{3}$

need greater understanding of IgE-dependent, IgE-independent, and non-immunologic mechanisms

need more comprehensive information about newly-discovered allergen triggers, allergens in some geographic areas, and certain groups of allergens, eg. reptile venoms and helminths

\footnotetext{
${ }^{1}$ Within high-resource countries, limited-resource areas can be found in inner cities, some rural areas, many public venues, and situations such as anaphylaxis on airplanes.

${ }^{2}$ In this Table, "limited-resource countries" include mid- and low-resource countries.

${ }^{3}$ In some limited-resource countries, fewer than $5 \%$ of deaths are certified with regard to cause.

CVD, cardiovascular disease; ICD, International Classification of Disease; MCAD; mast cell activation disorders; NSAIDs, non-steroidal anti-inflammatory drugs.
}

reliable epidemiologic information about anaphylaxis and its prevalence will remain under-estimated (Table 6).

At post-mortem, too, anaphylaxis can be under-diagnosed [36]; for example, when signs of anaphylaxis are absent and recognition is based only on circumstantial evidence and exclusion of other diseases [37]. Nevertheless, anaphylaxis fatality studies can sometimes provide unique information about triggers, presenting symptoms and signs, time course, and associated co-morbidities in a specific region or country.

\section{Patient-specific risk factors and co-factors relevant to anaphylaxis}

In all countries, improved recognition of patient vulnerability to anaphylaxis is needed as related to age, physiologic state (pregnancy), concomitant diseases, concurrent medications, and amplifying co-factors. In some countries, the prevalence of co-morbid diseases such as asthma or CVD might itself not be known (Table 6).

\section{Underlying mechanisms and anaphylaxis triggers}

Positive collaborations among physicians in academic centers and national allergy/immunology professional organizations in high-resource countries with those in mid- or low-resource countries are expanding our global knowledge of anaphylaxis mechanisms and triggers $[36,37,56,57,123]$. Despite this, in some countries, little information about anaphylaxis triggers, even the taxonomy of indigenous food plants and stinging insects, is available. Where potential triggers remain unidentified, lack of context for recognition of anaphylaxis can delay diagnosis and treatment (Table 6).

\section{Clinical diagnosis of anaphylaxis}

In all countries, improved training of healthcare professionals to recognize and treat anaphylaxis is needed, and the validated clinical criteria for anaphylaxis diagnosis need to be operationalized in order to optimize their usefulness. Where resources are limited, there can be inconsistent availability of basic services such as electricity and of equipment and supplies that aid in anaphylaxis diagnosis; for example, pulse oximeters to document oxygenation and sphygmomanometers and arm cuffs of various sizes to document blood pressure [125-130].

In such situations, assessment of hypoxemia is based on clinical indicators such as central cyanosis, nasal flaring, inability to speak or drink, grunting, lethargy, severe chest retractions, respiratory rate of more than 70 breaths/minute, and head-nodding; a capillary refill time of 2 seconds or less is documented to reflect a superior 
Table 7 Diagnosis of anaphylaxis: summary of unmet needs

\begin{tabular}{lll}
\hline & High-resource countries $^{\mathbf{1}}$ & Limited-resource countries $^{\mathbf{2}}$ \\
\hline Symptoms and signs (typically & need improved recognition and diagnosis & need improved recognition and diagnosis of \\
with onset in minutes to a few & of anaphylaxis and its sudden onset in & anaphylaxis and its sudden onset in relationship \\
hours after exposure; multi-system; & $\begin{array}{l}\text { relationship to exposure to a trigger (the } \\
\text { context) among all healthcare professionals }\end{array}$ & to exposure to a trigger (the context) among all \\
rapid progression) & $\begin{array}{l}\text { (including EMS personnel), patients, caregivers } \\
\text { and the public }\end{array}$ & the public
\end{tabular}

Clinical diagnosis of anaphylaxis

\begin{abstract}
Laboratory tests to confirm the clinical diagnosis eg. serum total tryptase measurement ${ }^{3}$
\end{abstract}

Differential diagnosis

Diagnosis of anaphylaxis in special populations need to operationalize the clinical criteria for the diagnosis of anaphylaxis by healthcare professionals; need improved coding for anaphylaxis and training of coders

need $\uparrow$ awareness of optimal timing of tests, and lack of test specificity (eg. $\uparrow$ tryptase in some patients with MI); need $\uparrow$ awareness that current lab tests are not useful at the time of patient presentation; need ongoing development of tests for biologic markers

need $\uparrow$ awareness that among the $>40$ entities in the differential diagnosis, acute asthma, acute urticaria, and panic or anxiety attacks are most common

need improved prompt recognition of anaphylaxis in infancy, adolescence, pregnancy, and advanced age need to operationalize the clinical criteria for the diagnosis of anaphylaxis; need $\uparrow$ availability of basic equipment and supplies to aid in recognition, eg. pulse oximetry and sphygmomanometers with arm cuffs of various sizes

need awareness that inability to measure tryptase levels (which is unlikely to be a priority for change due to high cost) is not a barrier to prompt diagnosis of anaphylaxis, which depends on recognition of symptoms and signs

need awareness that in some countries, pneumonia and sepsis are the most likely diagnoses in patients with sudden-onset respiratory distress and suddenonset hypotension/ distributive shock, respectively

need improved prompt recognition of anaphylaxis in infancy, adolescence, pregnancy, and advanced age

\footnotetext{
${ }^{1}$ Within high-resource countries, limited-resource areas can be found in inner cities, some rural areas, many public venues, and situations such as anaphylaxis on airplanes.

${ }^{2}$ In this Table, "limited-resource countries" include mid- and low-resource countries.

${ }^{3}$ The tryptase assay is standardized worldwide; in contrast, histamine assays are not standardized and are less practical for clinical use because of the need to refrigerate specimens.

EMS, emergency medical services; MI, myocardial infarction.
}

vena caval oxygen saturation of greater than $70 \%$. Assessment of hypotension and distributive shock is based on clinical indicators such as weak or non-palpable peripheral pulses [125-127] (Table 7).

In all countries, in the differential diagnosis of anaphylaxis, healthcare professionals should be aware of common considerations such as acute asthma, acute urticaria, and panic or anxiety attacks. In some countries, pneumonia is the most common consideration in patients presenting with acute-onset respiratory distress and hypoxemia, and sepsis is the most common consideration in those presenting with acute-onset hypotension or shock $[2-4,125,126]$ (Table 7$)$.

\section{Prompt initial treatment of anaphylaxis and monitoring}

In all countries, at the onset of an anaphylactic episode, it can be impossible to predict the rate of escalation or resolution of symptoms. Patients can present with deceptively mild symptoms such as hives, cough, or dizziness that rapidly increase in severity and culminate in fatality within minutes. Regardless of available resources, an important message to healthcare professionals, patients, caregivers, and the public is to recognize anaphylaxis promptly and as soon as it is recognized, inject lifesaving epinephrine in order to maximize the likelihood of survival [2-4].

\section{Box: The essentials of prompt initial anaphylaxis treatment}

- have an easy-to-follow and well-rehearsed protocol

- remove exposure to the trigger, if relevant

- inject epinephrine promptly intramuscularly in the mid-outer thigh

- call for help (resuscitation team in hospital or emergency medical services in community, if available)

- position the patient supine (or semi-reclining in a position of comfort if dyspneic or vomiting) and elevate the lower extremities

\section{If indicated at any time,}

- provide supplemental oxygen

- initiate IV fluid resuscitation with $0.9 \%$ saline

- perform cardiopulmonary resuscitation

- monitor BP, cardiac rate and function, and oxygen saturation

\section{See Table 8 for details.}

Where resources are limited, supplemental oxygen can be provided by oxygen concentrators instead of oxygen cylinders, and nasal prongs or nasopharyngeal catheters can be substituted for oxygen masks $[128,129]$; however, 
Table 8 Treatment of anaphylaxis in healthcare settings: summary of unmet needs

\begin{tabular}{lll}
\hline & High-resource countries & Limited-resource countries \\
\hline Prompt initial treatment of & need to encourage the "be prepared" & need to develop simple protocols, and focus on essentials: \\
anaphylaxis & approach: have a protocol, inject & inject epinephrine promptly IM in mid-outer thigh, call for \\
epinephrine promptly IM in mid-outer & help, position the patient appropriately; need to ensure the \\
& thigh, call for help, and position the patient & availability of epinephrine as an essential drug in $1 \mathrm{mg} / \mathrm{mL}$ \\
& appropriately; need to reduce the fear factor & ampules in all healthcare facilities, and improve availability of \\
& associated with epinephrine use by stressing & low-cost EAls (or if EAls are unaffordable, factory-sealed \\
& the good benefit/harm ratio of prompt IM & syringes prefilled with epinephrine 1 mg/mL)
\end{tabular}

Initial treatment (cont.)

Management of anaphylaxis refractory to initial treatment

\author{
Observation and monitoring in \\ healthcare settings
}

need to identify hospitals where patients with refractory anaphylaxis can receive skilled ventilatory and inotropic support from experienced, well-equipped personnel, and to list the contact information for these facilities on the anaphylaxis protocol

need $\uparrow$ availability of continuous electronic monitoring of cardiac rate, function, and blood pressure, and of pulse oximetry need $\uparrow$ availability of supplemental oxygen and IV fluids; where oxygen cylinders are not available, oxygen concentrators can be useful; lack of availability of supplemental oxygen and IV fluids is more critical than lack of second-line medications such as antihistamines and glucocorticoids, which are not essential for survival

need $\uparrow$ availability of supplemental oxygen and IV fluids such as $0.9 \%$ saline; need regular reassessment of availability of epinephrine, supplemental oxygen and IV fluids, supplies and equipment in hospitals

need $\uparrow$ availability of basic supplies and equipment for monitoring in many hospitals; and improved availability of continuous electronic monitoring of cardiac rate, function, and blood pressure, and pulse oximetry in teaching hospitals

${ }^{1}$ Within high-resource countries, limited-resource areas can be found in inner cities, some rural areas, many public venues, and situations such as anaphylaxis on airplanes.

${ }^{2}$ In this Table, "limited-resource countries" include mid- and low-resource countries.

EAls, epinephrine auto-injectors; IM, intramuscular; IV, intravenous.

in many hospitals, lack of availability of pulse oximetry for detecting hypoxemia and guiding oxygen therapy remains a critical concern [127]. Despite best efforts, treatment of anaphylaxis can, in some patients, be compromised by comorbidities such as anemia and reduced ability to achieve adequate oxygenation, or severe malnutrition and reduced ability to tolerate IV fluid resuscitation $[125,126]$ (Table 8).

Management of anaphylaxis refractory to initial treatment Even in high-resource countries, optimal treatment of refractory anaphylaxis is not available universally; for example, in remote, inaccessible, or impoverished areas or in specific situations such as anaphylaxis on airplanes. In limited-resource situations, lack of availability of basic essentials such as epinephrine, supplemental oxygen and IV fluid resuscitation is more critical than lack of second-line medications such as antihistamines and glucocorticoids. Lack of availability of advanced life-support management can be a major barrier to survival [72-76,128] (Table 8). In any limited-resource situation, resuscitation efforts prolonged over hours using a hand-held bag valve mask (manual resuscitator) are often successful in anaphylaxis [2] (Table 8).

In mid- and low-resource countries, striving to ensure more consistent availability of medications, supplies, and equipment for anaphylaxis treatment is an important goal [2,5-7]. The World Health Organization has developed a tool kit containing evidence-based guidelines and a framework for quality improvement in the hospital care of critically ill children in such environments [126], where despite many obstacles, improvements can be documented [130].

\section{Post-discharge management}

In high-resource countries, there is an increased focus on post-discharge management after successful treatment of anaphylaxis. Where resources are limited, post-discharge management is severely compromised by lack of availability of affordable auto-injectors or factory-sealed prefilled syringes containing epinephrine $[2,6,7]$. There are two alternative, although not preferred, options for epinephrine selfadministration. First, a $1 \mathrm{~mL}$ ampule of epinephrine and a $1 \mathrm{~mL}$ syringe can be provided; however, in a medical emergency, patients without medical training find it difficult to draw up a dose accurately and expel air from the syringe without losing the epinephrine. Second, an unsealed prefilled syringe containing the correct dose for the patient can be drawn up in advance by his/her physician; however, all or part of the dose can be lost, and epinephrine is stable for only 3-4 months in an unsealed syringe $[2,6,7]$.

Where resources are limited, local conditions typically determine the availability of follow-up with a healthcare professional and prevention of recurrent anaphylactic episodes is often compromised by lack of availability of physicians, tests to confirm triggers, and immune modulation (Table 9). 
Table 9 Treatment of anaphylaxis in community settings: summary of unmet needs

\begin{tabular}{lll}
\hline & High-resource countries $^{\mathbf{1}}$ & Limited-resource countries $^{\mathbf{2}}$ \\
\hline $\begin{array}{ll}\text { Discharge management of patients } \\
\text { treated for anaphylaxis }\end{array}$ & $\begin{array}{l}\text { need } \uparrow \text { public awareness of the importance } \\
\text { of prompt anaphylaxis recognition and }\end{array}$ & need $\uparrow$ availability of low-cost EAls or even \\
factory-sealed prefilled epinephrine syringes; & need $\uparrow$ awareness of alternative but not \\
& in the community; need $\uparrow$ availability of & preferred options (epinephrine $1 \mathrm{mg} / 1 \mathrm{~mL}$ \\
& low-cost EAls and of "stock" epinephrine ${ }^{3}$ in & ampules and $1 \mathrm{~mL}$ syringes, and unsealed \\
& schools, shopping malls, etc.; need a wider & syringes prefilled by healthcare professionals); \\
& range of epinephrine doses in auto-injectors, & need more information about epinephrine \\
& eg. 0.1 mg and 0.5 mg & shelf-life in extreme climates \\
Investigations to confirm anaphylaxis & need improved standardization of allergens and & need $\uparrow$ awareness that if sterile needles are \\
triggers & of test and challenge protocols; need $\uparrow$ awareness & available, allergen skin tests can be performed \\
& that allergen sensitization is far more common than & by skin prick or prick-prick testing with relevant \\
& clinical symptoms; and that tests for sensitization & foods, or skin testing with IV formulations \\
& must be selected and interpreted based on the & of medications \\
& history of the anaphylactic episode &
\end{tabular}

Prevention of anaphylaxis recurrences need improved public policies with regard to food labeling, improved school policies for anaphylaxis prevention and treatment, and improved access to specialists, including those who can document sensitization to novel triggers

Anaphylaxis education

Follow-up need $\uparrow$ availability of personalized anaphylaxis education by trained healthcare professionals and development of personalized emergency action plans that focus on recognition of symptoms and signs, implementation of the plan, prompt use of EAI, and wearing medical ID

need $\uparrow$ awareness of importance of follow-up with an allergist/ immunologist to provide training in anaphylaxis recognition, EAl use, allergen avoidance; and when indicated, immune modulation, eg. VIT need improved training of healthcare professionals to identify anaphylaxis triggers, symptoms, and signs; need $\uparrow$ availability of tests to confirm sensitization; (in their absence, trigger avoidance is based on the history); need $\uparrow$ availability of venom immunotherapy and desensitization to drugs

need $\uparrow$ awareness of anaphylaxis, improved training of healthcare professionals, and development of action plans to aid in recognition of anaphylaxis symptoms and signs; need improved availability of EAls

need $\uparrow$ awareness of the importance of follow-up after an acute anaphylactic episode; availability of follow-up will depend on local conditions

\footnotetext{
${ }^{1}$ Within high-resource countries, limited-resource areas can be found in inner cities, some rural areas, many public venues, and situations such as anaphylaxis on airplanes. ${ }^{2}$ In this Table, "limited-resource countries" include mid- and low-resource countries.

${ }^{3}$ Rationale: preventable deaths, especially in children, teenagers, and young adults occur in these venues; this issue is also listed in the research agenda (Table 11 ) because of the need to gather additional data.

EAIs, epinephrine auto-injectors; ID, identification; VIT, venom immunotherapy.
}

\section{International research agenda for anaphylaxis}

Anaphylaxis research has been hindered in the past by the perception that the disease is rare, absence of a universally accepted definition for clinical use, and lack of validated criteria for anaphylaxis diagnosis suitable for use in clinical and epidemiologic studies. Progress in these areas is giving momentum to basic, translational, and clinical anaphylaxis research.

ICON: Anaphylaxis proposes a comprehensive international research agenda for anaphylaxis (Tables 10 and 11) that extends and amplifies the anaphylaxis research agendas published independently by WAO and EAACI $[2,4]$. The ICON: Anaphylaxis research agenda is based in part on identification of areas where little or no high quality evidence is available to support the recommendations for anaphylaxis diagnosis, treatment, and prevention made in anaphylaxis guidelines and other publications.

Research tasks awaiting prioritization, as listed in Table 10, include operationalizing the clinical criteria for diagnosis and additional studies of epidemiology, patient risk factors, mechanisms, and triggers. Research tasks awaiting prioritization, as listed in Table 11, include further RCT of interventions, risk assessment, long-term risk reduction, and anaphylaxis education, as well as studies on anaphylaxis guidelines implementation and development of anaphylaxis pathways.

The ICON: Anaphylaxis research agenda will require regular updating and might take decades to complete, depending on the collaborations initiated and the financial support available. Prioritization of research questions is recommended. Initially this should involve identification of questions that are feasible to answer in the short-to-medium term, ideally guided by a formal consensus-building process involving basic scientists, methodologists, and clinician scientists.

Global collaborative efforts to date are improving the diagnosis and treatment of anaphylaxis [36,37,56,57,123]. They have identified the importance of using the validated clinical criteria to inform ICD-10 codes for improved accuracy of anaphylaxis identification at autopsy [36], and found differences between culprit allergens and circumstances of death from anaphylaxis in different countries [37]. They have also elucidated the role of novel anaphylaxis triggers, for example, flour mites [56] and short-chain 


\section{Table 10 International research agenda for anaphylaxis ${ }^{1,2}$}

\section{Epidemiology, Patient Risk Factors, Mechanisms, Triggers, and Diagnosis}

\section{Epidemiology of anaphylaxis}

Prospective studies of:

- global incidence and prevalence of anaphylaxis in general populations in different countries, in order to obtain reliable population estimates; ideally, concurrent studies will be performed

- anaphylaxis from all triggers, and from specific triggers including foods, stinging insect and other venoms, drugs, etc.

- anaphylaxis in different populations: infants, children, teenagers, pregnant women, the elderly, and patients with co-morbidities such as asthma, cardiovascular disease, and mast cell activation disorders

- the natural history of anaphylaxis based on well-designed longitudinal population-based investigations

\section{Patient risk factors for anaphylaxis}

Genotypes, phenotypes and endotypes of patients with anaphylaxis

Development of instruments to quantify patient-specific risk factors, ascertain their relative importance, and predict future anaphylactic episodes Biologic markers for identification of patients at risk

Prospective studies of the relationship between food-induced anaphylaxis and asthma, in order to ascertain the relationship of anaphylaxis severity and asthma control

Prospective studies of the relationship between food, insect venom, and drug-induced anaphylaxis and cardiovascular disease

Prospective studies of the relationship between anaphylaxis and mast cell activation disorders

Prospective studies of idiopathic anaphylaxis in patients of all ages

\section{Anaphylaxis mechanisms}

Further elucidation of mechanisms underlying anaphylaxis, including studies to improve understanding of molecular mechanisms

Studies of IgG-mediated anaphylaxis in humans

Additional studies of agents that can induce anaphylaxis through more than one mechanism, eg. radiocontrast media, biological agents such as infliximab, etc.

Further elucidation of the role of amplifying co-factors in anaphylaxis

\section{Triggers (causes, elicitors, inducers) of anaphylaxis}

Prospective studies of trends in triggers, to identify those that are becoming more (or less) common in different patient populations and in different global regions

Additional investigations of food cross-reactivities

Improved methods to detect hidden food allergens

Improved tests to confirm sensitization to anaphylaxis triggers that are uncommon in many countries, but relatively common in others; for example:

- foods such as buckwheat, silkworm pupa, bird's nest soup, chickpea, flour mites, maize, manioc

- stings and bites, eg. ants, caterpillars, jellyfish, lizards, scorpions, snakes

\section{Diagnosis of anaphylaxis}

Development of operationalized clinical criteria for the diagnosis of anaphylaxis

Validation of these operationalized clinical criteria for use in additional healthcare settings, in community settings, and in different countries

Development and validation of an algorithm for diagnosing anaphylaxis based on clinical criteria

Identification of additional biologic markers for identification of anaphylaxis

Further development of tests for biologic markers that might be useful for confirming the diagnosis of anaphylaxis at the time the patient presents

Development of protocols and algorithms to improve post-mortem identification of anaphylaxis as a cause of death

${ }^{1}$ Basic, clinical and applied sciences.

${ }^{2}$ This Table extends and amplifies the agendas for anaphylaxis research published independently by WAO and by EAACI.

galacto-oligosaccharides [57], and confirmed in a RCT that epinephrine pre-treatment reduced anaphylaxis to anti-snake venom by $43 \%$ and was superior to $\mathrm{H}_{1}$-antihistamine and glucocorticoid pre-treatment [123]. Global collaboration among investigators needs to be facilitated in order to accelerate future advances.

\section{Summary}

ICON: Anaphylaxis presents a harmonized approach to anaphylaxis diagnosis, treatment, and prevention based on the alignment found in the collaborating organizations' principal anaphylaxis guidelines. It documents consensus in the critically important areas of clinical diagnosis, 


\section{Table 11 International research agenda for anaphylaxis ${ }^{1,2}$}

\section{Management of Anaphylaxis in Healthcare and Community Settings, Risk Assessment and Reduction, and Education}

\section{Treatment in healthcare settings}

Epinephrine pharmacokinetic and pharmacodynamic studies in patients with different body mass indices

Additional comprehensive studies of epinephrine absorption after different routes of administration, including auto-injectors

Additional observational investigations of the safety of a first-aid dose of epinephrine ( $0.3 \mathrm{mg}$ intramuscularly) in patients with cardiovascular disease

Multicenter prospective randomized controlled trials to define the role of other pharmacologic interventions in anaphylaxis - examples include $\mathrm{H}_{1}$-antihistamines, $\mathrm{H}_{2}$-antihistamines, glucocorticoids, and glucagon

\section{Management in community settings}

Additional comparative studies of different epinephrine auto-injectors

- preference to carry, preference to use, and rate of occurrence of unintentional injections and injuries

Evaluation of the role of "stock" or "unassigned" epinephrine auto-injectors in public places, eg. schools, shopping malls

Further assessment of costs of epinephrine auto-injectors and their cost-effectiveness

Further evaluation of other routes of epinephrine administration, eg. sublingual, inhaled, intranasal

Prospective validation studies of anaphylaxis emergency action plans

Comparison of different anaphylaxis emergency action plans

Assessment of effectiveness of anaphylaxis emergency action plans

Assessment of school plans for anaphylaxis

\section{Risk assessment in anaphylaxis}

Further standardization of allergens, allergen skin test protocols, and allergen challenge protocols to facilitate comparisons among centers Further prospective studies of optimal timing of allergen skin tests after anaphylaxis to foods, venoms, drugs, and other allergens

Further development of in vitro tests such as component-resolved diagnostics and basophil activation tests to help distinguish asymptomatic sensitization from clinical risk

Development of new non-invasive tests to assess sensitization versus risk of clinical reactivity to drugs

\section{Long-term risk reduction in anaphylaxis}

Further prospective investigations of efficacy and safety of oral, sublingual, and epicutaneous immunotherapy to prevent recurrence of food-induced anaphylaxis and achieve immunologic tolerance

Further studies of the efficacy and safety of omalizumab pre-treatment and co-treatment with allergen immunotherapy

Studies of allergen immunotherapy to prevent anaphylaxis recurrences from less well-studied allergens, eg. natural rubber latex

Additional studies of immunotherapy to prevent recurrence of venom-induced anaphylaxis and immune modulation to prevent recurrence of drug-induced anaphylaxis

Additional prospective investigations of pharmacologic prophylaxis of iatrogenic anaphylaxis from radiocontrast media, biologic agents, snake anti-venom, allergen immunotherapy, etc.

Prospective investigations of the utility and cost-effectiveness of providing epinephrine auto-injectors to all patients receiving subcutaneous allergen immunotherapy with aeroallergens or venoms

\section{Anaphylaxis education}

Studies of methods to increase anaphylaxis awareness among patients, caregivers, and the public

Evaluation of educational programs for all physicians, including emergency medicine and primary care physicians

Evaluation of educational programs for other healthcare personnel, including nurses and paramedics

Evaluation of educational programs for patients at risk and caregivers

Studies of the unique needs of adolescents at risk for anaphylaxis recurrence in community settings and how best to communicate effectively with them

Evaluation of educational programs for the public

Studies of resistance to change and how to facilitate change

\section{Other}

Studies on anaphylaxis guidelines implementation

Studies on development of anaphylaxis pathways

${ }^{1}$ Basic, clinical and applied sciences.

${ }^{2}$ This Table extends and amplifies the agendas for anaphylaxis research published independently by WAO and by EAACI. 
treatment and prevention of anaphylaxis recurrences and, further, documents unmet needs in these areas. It recommends increasing the awareness of anaphylaxis, continuing to strengthen the evidence supporting recommendations for management and prevention, and improving dissemination and implementation of anaphylaxis guidelines. It proposes a comprehensive international anaphylaxis research agenda and calls for facilitation of increased collaborations among investigators in high-, mid- and low-resource countries. ICON: Anaphylaxis is a unique resource for physicians, other healthcare professionals, academics, policy-makers, patients, caregivers, and the public worldwide.

\begin{abstract}
Abbreviations
AAAAI: American Academy of Allergy Asthma and Immunology:

ACAAl: American College of Allergy, Asthma and Immunology;

ACE: Angiotensin-converting enzyme; BP: Blood pressure;

CVD: Cardiovascular disease; EAACl: European Academy of Allergy and Clinical Immunology; EAI: Epinephrine auto-injectors; EMS: Emergency medical services; iCAALL: International Collaboration in Asthma, Allergy and Immunology; ICD: International Classification of Disease; ICON: Anaphylaxis international consensus on anaphylaxis; ID: Identification; IM: Intramuscular; IV: Intravenous; MCAD: Mast cell activation disorder; MI: Myocardial infarction; NSAID: Non-steroidal anti-inflammatory drugs; OIT: Oral immunotherapy; RCT: Randomized controlled trials; RCM: Radiocontrast media; VIT: Venom immunotherapy; WAO: World Allergy Organization.
\end{abstract}

\section{Competing interests}

F. Estelle R. Simons: member, Medical Advisory Boards of ALK, Mylan, and Sanofi. Ledit Ardusso: no competing interests. Maria Beatrice Bilo: ALK, Meda. Victoria Cardona: has received fees as an advisor and speaker for ALK. Motohiro Ebisawa: no competing interests. Yehia El-Gamal: no competing interests. Phil Lieberman: member of the medical advisory boards of, and has been a consultant to, Mylan and Sanofi-Aventis; speaker for Mylan. Richard Lockey: no competing interests. Antonella Muraro: has served as advisor for and has received speaker fees from, Meda. Graham Roberts: member, Medical Advisory Board for ALK-Abello. Mario Sanchez-Borges: World Allergy Organization Executive Committee (President-Elect). Aziz Sheikh: has received honoraria for consultancy and/or research from ThermoFisher, ALK, Meda, and Allergy Therapeutics. Lynette Shek: no competing interests. Dana Wallace: advisor/consultant for Mylan and Sanofi. Margitta Worm: has received honoraria for consultation and lectures from Meda, ALK, and Allergopharma.

\section{Authors' contributions}

FERS led the development of the document and prepared the initial, interim, and final drafts. All authors contributed to the content of the document. All authors reviewed and approved the final document. Please see the "Methods" section on page 10 of this publication for details of the development process.

\section{Acknowledgments}

We acknowledge the support of the iCAALL Steering Committee (Chair Dr. Cezmi Akdis) and the World Allergy Organization. We thank Lori McNiven, Health Sciences Centre, Winnipeg, Manitoba, Canada for assistance.

\section{Author details}

'Department of Pediatrics \& Child Health and Department of Immunology, Faculty of Medicine, University of Manitoba, Room FE125, 820 Sherbrook Street, Winnipeg, Manitoba, Canada, R3A 1R9. ²Cátedra Neumonología, Alergia e Inmunología, Facultad de Ciencias Médicas, Universidad Nacional de Rosario, Rosario, Argentina. ${ }^{3}$ Allergy Unit, Department of Internal Medicine, University Hospital, Ancona, Italy. ${ }^{4}$ Allergy Section, Department of Internal Medicine, Hospital Universitari Vall d'Hebron, Barcelona, Spain. ${ }^{5}$ Department of Allergy, National Hospital Organization, Sagamihara National Hospital, Clinical Research Center for Allergy \& Rheumatology, Kanagawa, Japan. ${ }^{6}$ Pediatric Allergy and Immunology Unit, Ain Shams University, Cairo, Egypt. ${ }^{7}$ Allergy and Asthma Associates, Germantown, TN, USA. ${ }^{8}$ University of
South Florida Morsani College of Medicine, Tampa, FL, USA. ${ }^{9}$ Department of Women and Child Health, Food Allergy Referral Centre, University of Padua, Padua, Italy. ${ }^{10}$ University of Southampton Faculty of Medicine, Southampton United Kingdom, David Hide Asthma and Allergy Research Centre, St. Mary's Hospital, Isle of Wight, United Kingdom. ${ }^{11}$ Centro Medico Docente La Trinidad, Caracas, Clinica El Avila, Caracas, Venezuela. ${ }^{12}$ Center for Population Health Sciences, The University of Edinburgh, Edinburgh, United Kingdom and Division of General Internal Medicine and Primary Care, Brigham and Women's Hospital/Harvard Medical School, Boston, MA, USA. ${ }^{13}$ Department of Pediatrics, National University of Singapore, Singapore. ${ }^{14}$ Nova Southeastern University, Fort Lauderdale, FL, USA. ${ }^{15}$ Allergie-Centrum-Charité, Klinik fur Dermatologie und Allergologie, Charité, Universitatsmedizin, Berlin, Germany.

Received: 2 April 2014 Accepted: 3 April 2014 Published: 30 May 2014

\section{References}

1. Lotvall J, Pawankar R, Wallace DV, Akdis CA, Rosenwasser L, Weber RW, Burks AW, Casale TB, Lockey RF, Papadopoulos NG, Fineman SM, Ledford DK, on behalf of the AAAAl, the ACAAl, the EAACI, and the WAO: We call for iCAALL: International Collaboration in Asthma, Allergy and Immunology. J Allergy Clin Immunol 2012, 129:904-905.

2. Simons FER, Ardusso LRF, Bilo MB, El-Gamal YM, Ledford DK, Ring J, Sanchez-Borges M, Senna GE, Sheikh A, Thong BY, for the World Allergy Organization: World Allergy Organization guidelines for the assessment and management of anaphylaxis. J Allergy Clin Immunol 2011, 127:587-593. e1-e22.

3. Lieberman P, Nicklas RA, Oppenheimer J, Kemp SF, Lang DM, Bernstein DI, Bernstein JA, Burks AW, Feldweg AM, Fink JN, Greenberger PA, Golden DBK, James JM, Kemp SF, Ledford DK, Lieberman P, Sheffer AL, Bernstein DI, Blessing-Moore J, Cox L, Khan DA, Lang D, Nicklas RA, Oppenheimer J, Portnoy JM, Randolph C, Schuller DE, Spector SL, Tilles S, Wallace D: The diagnosis and management of anaphylaxis practice parameter: 2010 update. J Allergy Clin Immunol 2010, 126:477-480

4. Muraro A, Roberts G, Worm M, Bilo MB, Brockow K, Fernandez-Rivas M, Santos AF, Zolkipli ZQ, Bellou A, Bindslev-Jensen C, Cardona V, Clark AT, Demoly P, Dubois AEJ, Dunn Galvin A, Eigenmann P, Halken S, Harada L, Lack G, Jutel M, Niggemann B, Rueff F, Timmermans F, Vlieg-Boerstra BJ, Werfel T, Dhami S, Panesar S, Sheikh A, on behalf of EAACl Food Allergy and Anaphylaxis Guidelines Group: Anaphylaxis: Guidelines from the European Academy of Allergy and Clinical Immunology. Allergy 2014, DOl: 10.1111/all.12437.

5. Simons FER, for the World Allergy Organization: World Allergy Organization survey on global availability of essentials for the assessment and management of anaphylaxis by allergy/immunology specialists in healthcare settings. Ann Allergy Asthma Immunol 2010, 104:405-412.

6. Simons FER: Lack of worldwide availability of epinephrine autoinjectors for outpatients at risk of anaphylaxis. Ann Allergy Asthma Immunol 2005, 94:534-538.

7. Simons FER, for the World Allergy Organization: Epinephrine auto-injectors: first-aid treatment still out of reach for many at risk of anaphylaxis in the community. Ann Allergy Asthma Immunol 2009, 102:403-409.

8. Simons FER, Ardusso LRF, Bilo MB, Dimov V, Ebisawa M, El-Gamal YM, Ledford DK, Lockey RF, Ring J, Sanchez-Borges M, Senna GE, Sheikh A, Thong BY, Worm M, for the World Allergy Organization: 2012 update: World Allergy Organization Guidelines for the assessment and management of anaphylaxis. Curr Opin Allergy Clin Immunol 2012, 12:389-399.

9. Simons FER, Ardusso LRF, Dimov V, Ebisawa M, El-Gamal YM, Lockey RF, Sanchez-Borges M, Senna GE, Sheikh A, Thong BY, Worm M, for the World Allergy Organization: World Allergy Organization anaphylaxis guidelines: 2013 update of the evidence base. Int Arch Allergy Immunol 2013, 162:193-204.

10. Nicklas RA, Bernstein IL, Li JT, Lee RE, Spector SL, Dykewicz MS, Fineman S, Berger W, Blessing-Moore J, Schuller D, Joint Council of Allergy, Asthma, and Immunology Practice Parameters: The diagnosis and management of anaphylaxis. J Allergy Clin Immunol 1998, 101:S465-5528.

11. Joint Task Force on Practice Parameters, American Academy of Allergy Asthma and Immunology, American College of Allergy Asthma and Immunology, Joint Council of Allergy Asthma and Immunology: 
The diagnosis and management of anaphylaxis: an updated practice parameter. J Allergy Clin Immunol 2005, 115:S483-S523.

12. Campbell R, Li JT, Sadosty AT: Emergency department diagnosis and treatment of anaphylaxis. 2014 (in press).

13. Sampson HA, Bernstein D, Blessing-Moore J, Khan D, Lang D, Nicklas R, Oppenheimer J, Portnoy J, Randolph C, Schuller D, Spector S, Tilles SA, Wallace D: Food allergy: a practice parameter update. J Allergy Clin Immunol 2014, 133 (in press).

14. Golden DBK, Moffitt J, Nicklas RA, Freeman T, Graft DF, Reisman RE, Tracy JM: Stinging insect hypersensitivity: A practice parameter update 2011. J Allergy Clin Immunol 2011, 127:852-854. e23.

15. Joint Task Force on Practice Parameters, American Academy of Allergy Asthma and Immunology, American College of Allergy Asthma and Immunology, Joint Council of Allergy Asthma and Immunology: Drug allergy: an updated practice parameter. Ann Allergy Asthma Immunol 2010, 105:259-273.

16. Cox L, Nelson H, Lockey R, Calabria C, Chacko T, Finegold I, Nelson M, Weber R, Bernstein DI, Blessing-Moore J, Khan DA, Lang DM, Nicklas RA, Oppenheimer J, Portnoy JM, Randolph C, Schuller DE, Spector SL, Tilles S, Wallace D: Allergen immunotherapy: a practice parameter third update. J Allergy Clin Immunol 2011, 127:S1-S55.

17. Fineman S, Dowling P, O'Rourke D: Allergists' self-reported adherence to anaphylaxis practice parameters and perceived barriers to care: an American College of Allergy, Asthma, and Immunology member survey. Ann Allergy Asthma Immunol 2013, 111:529-536.

18. Brouwers MC, Kho ME, Browman GP, Burgers JS, Cluzeau F, Feder G, Fervers B, Graham ID, Grimshaw J, Hanna SE, Littlejohns P, Makarski J, Zitzelsberger L: AGREE II: advancing guideline development, reporting and evaluation in health care. Can Med Assoc J 2010, 182:E839-E842.

19. Muraro A, Roberts G, Clark A, Eigenmann PA, Halken S, Lack G, Moneret-Vautrin A, Niggemann B, Rance F: The management of anaphylaxis in childhood: position paper of the European Academy of Allergology and Clinical Immunology. Allergy 2007, 62:857-871.

20. Panesar SS, Javad S, de Silva D, Nwaru BI, Hickstein L, Muraro A, Roberts G, Worm M, Bilo MB, Cardona V, Dubois AEJ, Dunn Galvin A, Eigenmann P, Fernandez-Rivas M, Halken S, Lack G, Niggemann B, Santos AF, VliegBoerstra BJ, Zolkipli ZQ, Sheikh A: The epidemiology of anaphylaxis in Europe: a systematic review. Allergy 2013, 68:1353-1361.

21. Dhami S, Panesar SS, Roberts G, Muraro A, Worm M, Bilo MB, Cardona V, Dubois AEJ, DunnGalvin A, Eigenmann P, Fernandez-Rivas M, Halken $S$, Lack G, Niggemann B, Rueff F, Santos AF, Vlieg-Boerstra B, Zolkipli ZQ, Sheikh A, on behalf of the EAACI Food, Allergy and Anaphylaxis Guidelines Group: Management of anaphylaxis: a systematic review. Allergy 2014, 69:168-175.

22. Muraro A, Werfel T, Beyer K, Bindslev-Jensen C, Cardona V, Dubois AEJ, Du TG, Eigenmann P, Fernandez-Rivas M, Halken S, Hickstein L, Host A, Knol E, Lack G, Marchisotto MJ, Niggemann B, Nwaru B, Papadopoulos N, Roberts G, Santos A, Skypala I, Shoepfer A, Van Ree R, Venter C, Worm M, Vlieg-Boerstra BJ, Panesar SS, de Silva D, Soares-Weisser K, Sheikh A, Ballmer-Weber BK, Nilsson C, Akdis CA, Hoffmann-Sommergruber K: Diagnosis and management of food allergy: Guidelines from the European Academy of Allergy and Clinical Immunology. Allergy 2014, 69 (in press).

23. Sampson HA, Munoz-Furlong A, Campbell RL, Adkinson NF Jr, Bock SA, Branum A, Brown SGA, Camargo CA Jr, Cydulka R, Galli SJ, Gidudu J, Gruchalla RS, Harlor AD Jr, Hepner DL, Lewis LM, Lieberman PL, Metcalfe DD, O'Connor R, Muraro A, Rudman A, Schmitt C, Scherrer D, Simons FER, Thomas S, Wood JP, Decker WW: Second symposium on the definition and management of anaphylaxis: summary report-Second National Institute of Allergy and Infectious Disease/Food Allergy and Anaphylaxis Network symposium. J Allergy Clin Immunol 2006, 117:391-397.

24. Brown SGA, Stone SF, Fatovich DM, Burrows SA, Holdgate A, Celenza A, Coulson A, Hartnett L, Nagree Y, Cotterell C, Isbister GK: Anaphylaxis: Clinical patterns, mediator release, and severity. J Allergy Clin Immunol 2013, 132:1141-1149. e5.

25. Park HJ, Kim SH: Factors associated with shock in anaphylaxis. Am J Emerg Med 2012, 30:1674-1678.

26. Caffarelli C, Rico S, Rinaldi L, Povesi Dascola C, Terzi C, Bernasconi S: Blood pressure monitoring in children undergoing food challenge: association with anaphylaxis. Ann Allergy Asthma Immunol 2012, 108:285-286.

27. Gibbison B, Sheikh A, McShane P, Haddow C, Soar J: Anaphylaxis admissions to UK critical care units between 2005 and 2009. Anaesthesia 2012, 67:833-839.
28. Cetinkaya F, Incioglu A, Birinci S, Karaman BE, Dokucu Al, Sheikh A: Hospital admissions for anaphylaxis in Istanbul, Turkey. Allergy 2013, 68:128-130.

29. Hoffer V, Scheuerman O, Marcus N, Levy Y, Segal N, Lagovsky I, Monselise Y, Garty BZ: Anaphylaxis in Israel: experience with 92 hospitalized children. Pediatr Allergy Immunol 2011, 22:172-177.

30. Liew WK, Williamson E, Tang MLK: Anaphylaxis fatalities and admissions in Australia. J Allergy Clin Immunol 2009, 123:434-442.

31. Techapornroong M, Akrawinthawong K, Cheungpasitporn W, Ruxrungtham K: Anaphylaxis: a ten years inpatient retrospective study. Asian Pac $J$ Allergy Immunol 2010, 28:262-269.

32. Sole D, Ivancevich JC, Sanchez-Borges M: Anaphylaxis in Latin America: a report of the online Latin American Survey on Anaphylaxis (OLASA). Clinics (Sao Paulo) 2011, 66:943-947.

33. Worm M, Edenharter G, Rueff F, Scherer K, Pfohler C, Mahler V, Treudler R, Lang R, Nemat K, Koehli A, Niggemann B, Hompes S: Symptom profile and risk factors of anaphylaxis in Central Europe. Allergy 2012, 67:691-698.

34. Tejedor Alonso MA, Moro Moro M, Mugica Garcia MV, Esteban Hernandez J, Rosado Ingelmo A, Vila Albelda C, Gomez Traseira C, Cardenas Contreras R, Sanz Sacristan J, Hernandez MA: Incidence of anaphylaxis in the city of Alcorcon (Spain): a population-based study. Clin Exp Allergy 2012, 42:578-589.

35. Wood RA, Camargo CA, Lieberman P, Sampson HA, Schwartz LB, Zitt M, Collins C, Tringale M, Wilkinson M, Boyle J, Simons FER: Anaphylaxis in America: The prevalence and characteristics of anaphylaxis in the United States. J Allergy Clin Immunol 2014, 133:461-467.

36. Tanno LK, Ganem F, Demoly P, Toscano CM, Bierrenbach AL: Undernotification of anaphylaxis deaths in Brazil due to difficult coding under the ICD-10. Allergy 2012, 67:783-789.

37. Shen Y, Li L, Grant J, Rubio A, Zhao Z, Zhang X, Zhou L, Fowler D: Anaphylactic deaths in Maryland (United States) and Shanghai (China): a review of forensic autopsy cases from 2004 to 2006. Forensic Sci Int 2009, 186:1-5.

38. Simons FER: Anaphylaxis in infants: Can recognition and management be improved? J Allergy Clin Immunol 2007, 120:537-540

39. Simons FER, Schatz M: Anaphylaxis during pregnancy. J Allergy Clin Immunol 2012, 130:597-606.

40. Campbell RL, Hagan JB, Li JTC, Vukov SC, Kanthala AR, Smith VD, Manivannan V, Bellolio MF, Decker WW: Anaphylaxis in emergency department patients 50 or 65 years or older. Ann Allergy Asthma Immunol 2011, 106:401-406.

41. Gonzalez-Perez A, Aponte Z, Vidaurre CF, Rodriguez LAG: Anaphylaxis epidemiology in patients with and patients without asthma: a United Kingdom database review. J Allergy Clin Immunol 2010, 125:1098-1104. e1.

42. Iribarren C, Tolstykh IV, Miller MK, Eisner MD: Asthma and the prospective risk of anaphylactic shock and other allergy diagnoses in a large integrated health care delivery system. Ann Allergy Asthma Immunol 2010, 104:371-377.

43. Triggiani M, Patella V, Staiano Rl, Granata F, Marone G: Allergy and the cardiovascular system. Clin Exp Immunol 2008, 153(Suppl 1):7-11.

44. Kalesnikoff J, Galli SJ: New developments in mast cell biology. Nat Immunol 2008, 9:1215-1223.

45. Valent $P, A$ Akin $C$, Arock M, Brockow K, Butterfield JH, Carter MC, Castells M, Escribano L, Hartmann K, Lieberman P, Nedoszytko B, Orfao A, Schwartz LB, Sotlar K, Sperr WR, Triggiani M, Valenta R, Horny H-P, Metcalfe DD: Definitions, criteria and global classification of mast cell disorders with special reference to mast cell activation syndromes: a consensus proposal. Int Arch Allergy Immunol 2012, 157:215-225.

46. Rueff F, Przybilla B, Bilo MB, Muller U, Scheipl F, Aberer W, Birnbaum J, Bodzenta-Lukaszyk A, Bonifazi F, Bucher C, Campi P, Darsow U, Egger C, Haeberli G, Hawranek T, Korner M, Kucharewicz I, Kuchenhoff H, Lang R, Quercia O, Reider N, Severino M, Sticherling M, Sturm GJ, Wuthrich B: Predictors of severe systemic anaphylactic reactions in patients with Hymenoptera venom allergy: importance of baseline serum tryptase-a study of the European Academy of Allergology and Clinical Immunology Interest Group on Insect Venom Hypersensitivity. J Allergy Clin Immunol 2009, 124:1047-1054.

47. Alvarez-Twose I, Vano-Galvan S, Sanchez-Munoz L, Morgado JM, Matito A, Torrelo A, Jaen P, Schwartz LB, Orfao A, Escribano L: Increased serum baseline tryptase levels and extensive skin involvement are predictors for the severity of mast cell activation episodes in children with mastocytosis. Allergy 2012, 67:813-821. 
48. Lee S, Hess EP, Nestler DM, Bellamkonda Athmaram VR, Bellolio MF, Decker WW, Li JTC, Hagan JB, Manivannan V, Vukov SC, Campbell RL: Antihypertensive medication use is associated with increased organ system involvement and hospitalization in emergency department patients with anaphylaxis. J Allergy Clin Immunol 2013, 131:1103-1108.

49. Stoevesandt J, Hain J, Kerstan A, Trautmann A: Over- and underestimated parameters in severe Hymenoptera venom-induced anaphylaxis: cardiovascular medication and absence of urticaria/angioedema. J Allergy Clin Immunol 2012, 130:698-704.

50. Wolbing F, Fischer J, Koberle M, Kaesler S, Biedermann T: About the role and underlying mechanisms of cofactors in anaphylaxis. Allergy 2013, 68:1085-1092.

51. Bauer CS, Kampitak T, Messieh ML, Kelly KJ, Vadas P: Heterogeneity in presentation and treatment of catamenial anaphylaxis. Ann Allergy Asthma Immunol 2013, 111:107-111.

52. Khodoun MV, Strait R, Armstrong L, Yanase N, Finkelman FD: Identification of markers that distinguish $\lg \mathrm{E}$ - from IgG-mediated anaphylaxis. Proc Nat Acad Sci USA 2011, 108:12413-12418.

53. Boyce JA, Assa'ad AH, Burks AW, Jones SM, Sampson HA, Wood RA, Plaut M, Cooper SF, Fenton M, Arshad SH, Bahna SL, Beck LA, Byrd-Bredbenner C, Camargo CA Jr, Eichenfield L, Furuta GT, Hanifin JM, Jones C, Kraft M, Levy BD, Lieberman P, Luccioli S, McCall KM, Schneider LC, Simon RA, Simons FER, Teach SJ, Yawn BP: Guidelines for the diagnosis and management of food allergy in the United States: report of the NIAID-sponsored expert panel. J Allergy Clin Immunol 2010, 126:S1-S58

54. Liew WK, Chiang WC, Goh AE, Lim HH, Chay OM, Chang S, Tan JH, Shih E, Kidon M: Paediatric anaphylaxis in a Singaporean children cohort: changing food allergy triggers over time. Asia Pac Allergy 2013, 3:29-34.

55. Vereda A, van Hage M, Ahlstedt S, Ibanez MD, Cuesta-Herranz J, van Odijk J, Wickman M, Sampson HA: Peanut allergy: Clinical and immunologic differences among patients from 3 different geographic regions. J Allergy Clin Immunol 2011, 127:603-607.

56. Sanchez-Borges M, Suarez Chacon R, Capriles-Hulett A, Caballero-Fonseca F, Fernandez-Caldas E: Anaphylaxis from ingestion of mites: pancake anaphylaxis. J Allergy Clin Immunol 2013, 131:31-35.

57. Chiang WC, Huang C-H, Llanora GV, Gerez I, Goh SH, Shek LPC, Nauta AJ, Van Doorn WA, Bindels J, Ulfman LH, Knipping K, Delsing DJ, Knol EF, Lee BW: Anaphylaxis to cow's milk formula containing short-chain galacto-oligosaccharide. J Allergy Clin Immunol 2012, 130:1361-1367.

58. Takahashi H, Matsuo H, Chinuki Y, Kohno K, Tanaka A, Maruyama N, Morita E: Recombinant high molecular weight-glutenin subunit-specific $\lg$ E detection is useful in identifying wheat-dependent exercise-induced anaphylaxis complementary to recombinant omega- 5 gliadin-specific IgE test. Clin Exp Allergy 2012, 42:1293-1298.

59. Brown SGA, van Eeden P, Wiese MD, Mullins RJ, Solley GO, Puy R, Taylor RW, Heddle RJ: Causes of ant sting anaphylaxis in Australia: the Australian Ant Venom Allergy Study. Med J Aust 2011, 195:69-73.

60. Ribeiro-Vaz I, Marques J, Demoly P, Polonia J, Gomes ER: Drug-induced anaphylaxis: a decade review of reporting to the Portuguese Pharmacovigilance Authority. Eur J Clin Pharmacol 2013, 69:673-681.

61. Renaudin J-M, Beaudouin E, Ponvert C, Demoly P, Moneret-Vautrin D-A: Severe drug-induced anaphylaxis: analysis of 333 cases recorded by the Allergy Vigilance Network from 2002 to 2010. Allergy 2013, 68:929-937.

62. Mertes PM, Alla F, Trechot P, Auroy $Y$, Jougla E, and the Groupe d'Etudes des Reactions Anaphylactoides Peranesthesiques: Anaphylaxis during anesthesia in France: an 8-year national survey. J Allergy Clin Immunol 2011, 128:366-373.

63. Kim J, Park MR, Kim DS, Lee JO, Maeng SH, Cho SY, Han Y, Ahn K, Jin DK: IgE-mediated anaphylaxis and allergic reactions to idursulfase in patients with Hunter syndrome. Allergy 2013, 68:796-802.

64. Brockow K, Ring J: Anaphylaxis to radiographic contrast media. Curr Opin Allergy Clin Immunol 2011, 11:326-331.

65. Minciullo PL, Cascio A, David A, Pernice LM, Calapai G, Gangemi S: Anaphylaxis caused by helminths: review of the literature. Eur Rev Med Pharmacol Sci 2012, 16:1513-1518.

66. Li Y, Zheng H, Cao X, Liu Z, Chen L: Demographic and clinical characteristics of patients with anaphylactic shock after surgery for cystic echinococcosis. Am J Trop Med Hyg 2011, 85:452-455.

67. Campbell RL, Hagan JB, Manivannan V, Decker WW, Kanthala AR, Bellolio MF, Smith VD, Li JTC: Evaluation of National Institute of Allergy and Infectious Diseases/Food Allergy and Anaphylaxis Network criteria for the diagnosis of anaphylaxis in emergency department patients. J Allergy Clin Immunol 2012, 129:748-752.
68. Harduar-Morano L, Simon MR, Watkins S, Blackmore C: Algorithm for the diagnosis of anaphylaxis and its validation using population-based data on emergency department visits for anaphylaxis in Florida. J Allergy Clin Immunol 2010, 126:98-104

69. Vadas P, Perelman B, Liss G: Platelet-activating factor, histamine, and tryptase levels in human anaphylaxis. J Allergy Clin Immunol 2013, 131:144-149.

70. Sala-Cunill A, Cardona V, Labrador-Horrillo M, Luengo O, Esteso O, Garriga T, Vicario M, Guilarte M: Usefulness and limitations of sequential serum tryptase for the diagnosis of anaphylaxis in 102 patients. Int Arch Allergy Immunol 2013, 160:192-199.

71. Belhocine W, Ibrahim Z, Grandne V, Buffat C, Robert P, Gras D, Cleach I, Bongrand $\mathrm{P}$, Carayon $\mathrm{P}$, Vitte J: Total serum tryptase levels are higher in young infants. Pediatr Allergy Immunol 2011, 22:600-607.

72. Choo KJL, Simons FER, Sheikh A: Glucocorticoids for the treatment of anaphylaxis. Cochrane Database Syst Rev 2012, 4, CD007596.

73. Sheikh A, Ten Broek V, Brown SGA, Simons FER: $\mathrm{H}_{1}$-antihistamines for the treatment of anaphylaxis: Cochrane systematic review. Allergy 2007, 62:830-837.

74. Ellis BC, Brown SGA: Parenteral antihistamines cause hypotension in anaphylaxis. Emerg Med Australas 2013, 25:92-93.

75. Nurmatov $U$, Rhatigan $E$, Simons FER, Sheikh A: $\mathrm{H}_{2}$-antihistamines for the treatment of anaphylaxis with and without shock: a systematic review. Ann Allergy Asthma Immunol 2014, 112:126-131.

76. Field JM, Hazinski MF, Sayre MR, Chameides L, Schexnayder SM, Hemphill R, Samson RA, Kattwinkel J, Berg RA, Bhanji F, Cave DM, Jauch EC, Kudenchuk PJ, Neumar RW, Peberdy MA, Perlman JM, Sinz E, Travers AH, Berg MD, Billi JE, Eigel B, Hickey RW, Kleinman ME, Link MS, Morrison LJ, O'Connor RE, Shuster M, Callaway CW, Cucchiara B, Ferguson JD, Rea TD, Vanden Hoek TL: Part 1: executive summary: 2010 American Heart Association Guidelines for Cardiopulmonary Resuscitation and Emergency Cardiovascular Care. Circulation 2010, 122:S640-S656.

77. Vadas P, Perelman B: Effect of epinephrine on platelet-activating factor-stimulated human vascular smooth muscle cells. J Allergy Clin Immunol 2012, 129:1329-1333.

78. Rudders SA, Geyer BC, Banerji A, Phipatanakul W, Clark S, Camargo CA Jr: Obesity is not a risk factor for repeat epinephrine use in the treatment of anaphylaxis. J Allergy Clin Immunol 2012, 130:1216-1218.

79. Grabenhenrich L, Hompes S, Gough H, Rueff F, Scherer K, Pfohler C, Treudler R, Mahler V, Hawranek T, Nemat K, Koehli A, Keil T, Worm M: Implementation of anaphylaxis management guidelines: a register-based study. PLoS One 2012, 7:e35778.

80. Arroabarren E, Lasa EM, Olaciregui I, Sarasqueta C, Munoz JA, Perez-Yarza EG: Improving anaphylaxis management in a pediatric emergency department. Pediatr Allergy Immunol 2011, 22:708-714.

81. Ben-Shoshan M, La Vieille S, Eisman H, Alizadehfar R, Mill C, Perkins E, Joseph L, Morris J, Clarke A: Anaphylaxis treated in a Canadian pediatric hospital: Incidence, clinical characteristics, triggers, and management. J Allergy Clin Immunol 2013, 132:739-741. e3.

82. Perel $\mathrm{P}$, Roberts I, Ker K: Colloids versus crystalloids for fluid resuscitation in critically ill patients. Cochrane Database Syst Rev 2013, 2, CD000567.

83. Jang DH, Nelson LS, Hoffman RS: Methylene blue for distributive shock: A potential new use of an old antidote. J Med Toxicol 2013, 9:242-249.

84. Sheikh A, Simons FER, Barbour V, Worth A: Adrenaline auto-injectors for the treatment of anaphylaxis with and without cardiovascular collapse in the community. Cochrane Database Syst Rev 2012, 8, CD008935.

85. Landsman-Blumberg PB, Wei W, Douglas D, Smith DM, Clark S, Camargo CA Jr: Food-induced anaphylaxis among commercially insured US adults: patient concordance with postdischarge care guidelines. J Allergy Clin Immunol Pract 2013, 1:595-601.

86. Rudders SA, Clark S, Wei W, Camargo CA Jr: Longitudinal study of 954 patients with stinging insect anaphylaxis. Ann Allergy Asthma Immunol 2013, 111:199-204. e1.

87. Fleischer DM, Perry TT, Atkins D, Wood RA, Burks AW, Jones SM, Henning AK, Stablein D, Sampson HA, Sicherer SH: Allergic reactions to foods in preschool-aged children in a prospective observational food allergy study. Pediatrics 2012, 130:e25-e32.

88. Noimark L, Wales J, Du Toit G, Pastacaldi C, Haddad D, Gardner J, Hyer W, Vance G, Townshend C, Alfaham M, Arkwright PD, Rao R, Kapoor S, Summerfield A, Warner JO, Roberts G: The use of adrenaline autoinjectors by children and teenagers. Clin Exp Allergy 2012, 42:284-292.

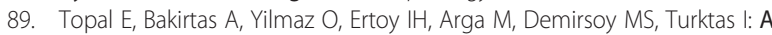
real-life study on acquired skills from using an adrenaline autoinjector. Int Arch Allergy Immunol 2013, 160:301-306. 
90. Arga M, Bakirtas A, Catal F, Derinoz O, Harmanci K, Razi CH, Ergocen S, Demirsoy MS, Turktas I: Training of trainers on epinephrine autoinjector use. Pediatr Allergy Immunol 2011, 22:590-593.

91. Brown J, Tuthill D, Alfaham M, Spear E: A randomized maternal evaluation of epinephrine autoinjection devices. Pediatr Allergy Immunol 2013, 24:173-177.

92. Chad L, Ben-Shoshan M, Asai Y, Cherkaoui S, Alizadehfar R, St-Pierre Y, Harada L, Allen M, Clarke A: A majority of parents of children with peanut allergy fear using the epinephrine auto-injector. Allergy 2013, 68:1605-1609.

93. Edwards ES, Gunn R, Simons FER, Carr K, Chinchilli VM, Painter G, Goldwater R: Bioavailability of epinephrine from Auvi-Q compared with EpiPen. Ann Allergy Asthma Immunol 2013, 111:132-137.

94. Camargo CA Jr, Guana A, Wang S, Simons FER: Auvi-Q versus EpiPen: preferences of adults, caregivers and children. J Allergy Clin Immunol Pract 2013, 1:266-272.

95. Simons E, Sicherer SH, Simons FER: Timing the transfer of responsibilities for anaphylaxis recognition and use of an epinephrine auto-injector from adults to children and teenagers: pediatric allergists' perspective. Ann Allergy Asthma Immunol 2012, 108:321-325.

96. Sicherer SH, Vargas PA, Groetch ME, Christie L, Carlisle SK, Noone S, Jones SM: Development and validation of educational materials for food allergy. J Pediatr 2012, 160:651-656.

97. Kelleher MM, Dunn Galvin A, Sheikh A, Cullinane C, Fitzsimons J, Hourihane JO'B: Twenty four-hour helpline access to expert management advice for food-allergy-triggered anaphylaxis in infants, children and young people: a pragmatic, randomized controlled trial. Allergy 2013, 68:1598-1604

98. Armstrong N, Wolff R, van Mastrigt G, Martinez N, Hernandez AV, Misso K, Kleijnen J: A systematic review and cost-effectiveness analysis of specialist services and adrenaline auto-injectors in anaphylaxis. Health Technol Assess 2013, 17:1-117.

99. Sicherer SH, Sampson HA: Food allergy: epidemiology, pathogenesis, diagnosis, and treatment. J Allergy Clin Immunol 2014, 133:291-307.

100. Heinzerling L, Mari A, Bergmann K-C, Bresciani M, Burbach G, Darsow U, Durham S, Fokkens W, Gjomarkaj M, Haahtela T, Bom AT, Wohrl S, Maibach H, Lockey R: The skin prick test - European standards. Clin Transl Allergy 2013, 3:3

101. Ludman S, Wassenberg J, Du Toit G, Fox AT, Lack G, Eigenmann PA: Paediatric oral peanut challenges: a comparison of practice in London and Western Switzerland. Allergy 2013, 68:539-541.

102. Sampson HA, Gerth van Wijk R, Bindslev-Jensen C, Sicherer S, Teuber SS, Burks AW, Dubois AEJ, Beyer K, Eigenmann PA, Spergel JM, Werfel T, Chinchilli VM: Standardizing double-blind, placebo-controlled oral food challenges: American Academy of Allergy, Asthma \& Immunology-European Academy of Allergy and Clinical Immunology PRACTALL consensus report. J Allergy Clin Immunol 2012, 130:1260-1274.

103. Strohmeier B, Aberer W, Bokanovic D, Komericki P, Sturm GJ: Simultaneous intradermal testing with hymenoptera venoms is safe and more efficient than sequential testing. Allergy 2013, 68:542-544.

104. Thong BY, Mirakian R, Castells M, Pichler W, Romano A, Bonadonna P, Diana D, Kowalski M, Yanez A, Lleonart R, Sanchez-Borges M, Demoly P: World Allergy Organization international survey on diagnostic procedures and therapies in drug allergy/hypersensitivity. World Allergy Organ J 2011, 4:257-270.

105. Sanchez-Borges M, Thong B, Blanca M, Ensina LF, Gonzalez-Diaz S, Greenberger PA, Jares E, Jee Y-K, Kase-Tanno L, Khan D, Park J-W, Pichler W, Romano A, Jaen MJ: Hypersensitivity reactions to non beta-lactam antimicrobial agents, a statement of the WAO special committee on drug allergy. World Allergy Organ J 2013, 6:18

106. Lafuente A, Javaloyes G, Berroa F, Goikoetxea MJ, Moncada R, Nunez-Cordoba JM, Cabrera-Freitag P, D'Amelio C, Sanz ML, Gastaminza G: Early skin testing is effective for diagnosis of hypersensitivity reactions occurring during anesthesia. Allergy 2013, 68:820-822.

107. Ng IE, Turner PJ, Kemp AS, Campbell DE: Parental perceptions and dietary adherence in children with seafood allergy. Pediatr Allergy Immunol 2011, 22:720-728

108. Vale S, Smith J, Said M, Dunne G, Mullins R, Loh R: ASCIA guidelines for prevention of anaphylaxis in schools, pre-schools and childcare: 2012 update. J Paediatr Child Health 2013, 49:342-345.

109. Barnett J, Botting N, Gowland MH, Lucas JS: The strategies that peanut and nut-allergic consumers employ to remain safe when travelling abroad. Clin Transl Allergy 2012, 2:12.

110. Cummings AJ, Knibb RC, King RM, Lucas JS: The psychosocial impact of food allergy and food hypersensitivity in children, adolescents and their families: a review. Allergy 2010, 65:933-945.
111. Shemesh E, Annunziato RA, Ambrose MA, Ravid NL, Mullarkey C, Rubes M, Chuang K, Sicherer M, Sicherer SH: Child and parental reports of bullying in a consecutive sample of children with food allergy. Pediatrics 2013, 131:e10-e17.

112. Boyle RJ, Elremeli M, Hockenhull J, Cherry MG, Bulsara MK, Daniels M, Oude Elberink JNG: Venom immunotherapy for preventing allergic reactions to insect stings. Cochrane Database Syst Rev 2012, 10, CD008838.

113. Bilo MB, Antonicelli L, Bonifazi F: Honeybee venom immunotherapy: certainties and pitfalls. Immunotherapy 2012, 4:1153-1166.

114. Brown SGA, Wiese MD, van Eeden P, Stone SF, Chuter CL, Gunner J, Wanandy T, Phillips M, Heddle RJ: Ultrarush versus semirush initiation of insect venom immunotherapy: a randomized controlled trial. J Allergy Clin Immunol 2012, 130:162-168.

115. Rueff F, Chatelain R, Przybilla B: Management of occupational Hymenoptera allergy. Curr Opin Allergy Clin Immunol 2011, 11:69-74.

116. Bonadonna P, Gonzalez-de-Olano D, Zanotti R, Riccio AM, Matito A, Vega A, Passalacqua G: Venom immunotherapy in patients with clonal mast cell disorders: efficacy, safety, and practical considerations. J Allergy Clin Immunol Pract 2013, 1:474-478.

117. Liu A, Fanning L, Chong H, Fernandez J, Sloane D, Sancho-Serra M, Castells $M$ : Desensitization regimens for drug allergy: state of the art in the 21st century. Clin Exp Allergy 2011, 41:1679-1689.

118. Gibbs NM, Sadleir PH, Clarke RC, Platt PR: Survival from perioperative anaphylaxis in Western Australia 2000-2009. Br J Anaesthesia 2013, 111:589-593.

119. Wood RA, Sampson HA: Oral immunotherapy for the treatment of peanut allergy: is it ready for prime time? J Allergy Clin Immunol Pract 2014, 2:97-98.

120. Jones SM, Burks AW, Dupont C: State of the art on food allergen immunotherapy: oral, sublingual, and epicutaneous. J Allergy Clin Immunol 2014, 133:318-323.

121. Schneider LC, Rachid R, Lebovidge J, Blood E, Mittal M, Umetsu DT: A pilot study of omalizumab to facilitate rapid oral desensitization in high-risk peanut-allergic patients. J Allergy Clin Immunol 2013, 132:1368-1374.

122. Kim S-H, Lee S-H, Lee S-M, Kang H-R, Park H-W, Kim S-S, Cho S-H, Min K-U, Kim Y-Y, Chang Y-S: Outcomes of premedication for non-ionic radio-contrast media hypersensitivity reactions in Korea. Eur J Radiol 2011, 80:363-367.

123. de Silva HA, Pathmeswaran A, Ranasinha CD, Jayamanne S, Samarakoon SB, Hittharage A, Kalupahana R, Ratnatilaka GA, Uluwatthage W, Aronson JK, Armitage JM, Lalloo DG, de Silva HJ: Low-dose adrenaline, promethazine, and hydrocortisone in the prevention of acute adverse reactions to antivenom following snakebite: a randomised, double-blind, placebo-controlled trial. PLoS Med 2011, 8:e1000435.

124. Muller UR, Jutel M, Reimers A, Zumkehr J, Huber C, Kriegel C, Steiner U, Haeberli G, Akdis M, Helbling A, Schnyder B, Blaser K, Akdis C: Clinical and immunologic effects of $\mathrm{H}_{1}$-antihistamine preventive medication during honeybee venom immunotherapy. J Allergy Clin Immunol 2008, 122:1001-1007.

125. Ralston ME, Day LT, Slusher TM, Musa NL, Doss HS: Global paediatric advanced life support: improving child survival in limited-resource settings. Lancet 2013, 381:256-265.

126. Pocket Book of Hospital care for children: Guidelines for the management of common childhood illnesses. 2nd edition. Geneva, Switzerland: World Health Organization; 2013:108-109.

127. Raimer PL, Han YY, Weber MS, Annich GM, Custer JR: A normal capillary refill time of $\leq 2$ seconds is associated with superior vena cava oxygen saturations of $\geq 70 \%$. J Pediatr 2011, 158:968-972.

128. Duke T, Graham SM, Cherian MN, Ginsburg AS, English M, Howie S, Peel D, Enarson PM, Wilson $1 \mathrm{H}$, Were W: Oxygen is an essential medicine: a call for international action. Int J Tuberc Lung Dis 2010, 14:1362-1368.

129. Enarson P, La Vincente S, Gie R, Maganga E, Chokani C: Implementation of an oxygen concentrator system in district hospital paediatric wards throughout Malawi. Bull World Health Organ 2008, 86:344-348.

130. Campbell H, Duke T, Weber M, English M, Carai S, Tamburlini G: Global initiatives for improving hospital care for children: state of the art and future prospects. Pediatrics 2008, 121:e984-992.

doi:10.1186/1939-4551-7-9

Cite this article as: Simons et al:: International consensus on (ICON) anaphylaxis. World Allergy Organization Journal 2014 7:9. 